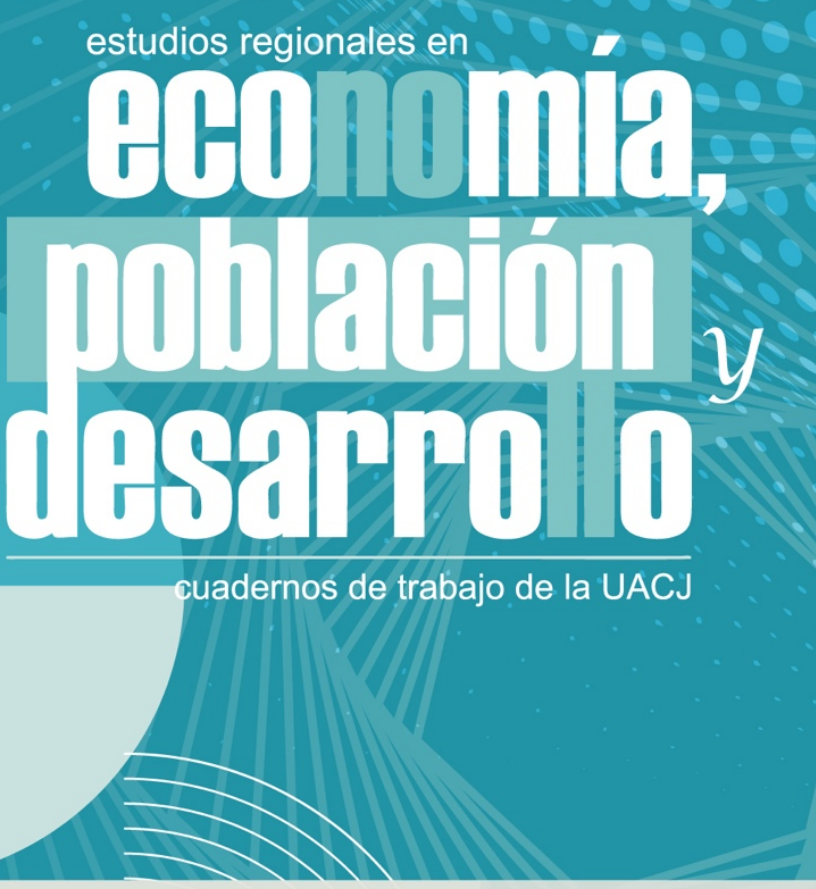

Isotopías de sostenibilidad urbana y regional en el Estado de México

María Estela Orozco-Hernández

UNIVERSIDAD AUTÓNOMA DE CIUDAD JUÁREZ

PUBLICACIÓN AFILIADA A LA

RED IBEROAMERICANA DE ESTUDIOS DEL DESARROLLO 


\title{
Isotopías de sostenibilidad urbana y regional en el Estado de México
}

María Estela Orozco-Hernández

\author{
UNIVERSIDAD AUTÓNOMA DE CIUDAD JUÁREZ \\ PUBLICACIÓN AFILIADA A LA \\ RED IBEROAMERICANA DE ESTUDIOS DEL DESARROLLO
}




\title{
UNIVERSIDAD AUTÓNOMA DE CIUDAD JUÁREZ
}

\author{
PUBLICACIÓN AFILIADA A LA \\ RED IBEROAMERICANA DE ESTUDIOS DEL DESARROLLO
}

Universidad Autónoma de Ciudad Juárez

2018-2024

Mtro. Juan Ignacio Camargo Nassar

Rector

Mtro. Daniel Alberto Constandse Cortez

Secretario General

Mtro. Santos Alonso Morales Muñoz

Director del Instituto de Ciencias Sociales y Administración

Mtro. Jesús Meza Vega

Director General de Comunicación Universitaria

Comité de Coordinación de la Red Iberoamericana

de Estudios del Desarrollo 2018-2020

Dra. Paulina Sanhueza Martínez (Universidad de la Frontera, Chile)

Coordinadora General

Dr. Ignacio Rodríguez Rodríguez (Universidad de la Frontera, Chile)

Secretario general

Dra. Myrna Limas Hernández

(Universidad Autónoma de Ciudad Juárez, México)

Vocal de Organización

Dr. Pablo Galaso Reca (Universidad de la República, Uruguay)

Vocal de Organización

Dr. Luis Enrique Gutiérrez Casas

Director y editor de Cuadernos de Trabajo

Estudios Regionales en Economía, Población y Desarrollo

Comité editorial

Sección internacional

Dra. Sofía Boza Martínez

(Universidad de Chile, Chile)

Dra. Olga Biosca Artiñano

(Glasgow Caledonian University, Reino Unido)

Dra. Ángeles Sánchez Díez

(Universidad Autónoma de Madrid, España)

Dr. Thomas Fullerton Mankin

(University of Texas at El Paso, Estados Unidos)

Dr. Adrián Rodríguez Miranda

(Universidad de la República, Uruguay)

Dra. Ikuho Kochi

(Kanazawa University, Japón)

Dr. Pablo Galaso Reca

(Universidad de la República, Uruguay)

Sección local

(Universidad Autónoma de Ciudad Juárez)

Dra. Myrna Limas Hernández

Dra. Rosa María García Almada

Dr. Raúl Alberto Ponce Rodríguez

Dr. Isaac Leobardo Sánchez Juárez

Dr. Héctor Alonso Barajas Bustillos

Dr. Juan Carlos Medina Guirado

Mtra. María Del Socorro Velázquez Vargas

Diseño de cubierta

Abigail Bautista
Estudios Regionales en Economía, Población

y Desarrollo. Cuadernos de Trabajo de la UACJ

ISSN 2007-3739

Número 64. Julio - Agosto 2021

Isotopías de sostenibilidad urbana y regional

en el Estado de México

María Estela Orozco-Hernández

Universidad Autónoma de Ciudad Juárez

Estudios Regionales en Economía, Población y Desarrollo.

Cuadernos de Trabajo de la UACJ

Año 11, No. 64 julio - agosto 2021, es una publicación bimestral editada por la Universidad Autónoma de Ciudad Juárez a través del Cuerpo Académico de Estudios Regionales en Economía, Población y Desarrollo del Instituto de Ciencias Sociales y Administración. Redacción: Avenida Universidad y H. Colegio Militar, Zona Chamizal s/n., C.P. 32300, Ciudad Juárez, Chihuahua, México.

Teléfonos: (656) 688-38-00, ext.3792. Correo electrónico: igtz@uacj.mx. Editor responsable: Luis Enrique Gutiérrez Casas. Reserva de derechos al uso exclusivo: edición impresa, ISSN 2007-3739., edición digital, No. de reserva 04-2019-050218151500. Impresa por Studio Los Dorados, calle Del Campanario, número 820-2, Santa Cecilia, C.P. 32350, Cd. Juárez, Chihuahua. Distribuidor: Subdirección de Gestión de Proyecto y Marketing Editorial. Ave. Plutarco Elías Calles 1210, Foviste Chamizal, C.P. 32310, Ciudad Juárez, Chihuahua. Este número se terminó de imprimir el 15 de junio 2021 con un tiraje de 120 ejempares.

Los ensayos publicados son responsabilidad exclusiva de sus autores.

Se autoriza la reproducción total o parcial bajo condición de citar la fuente.

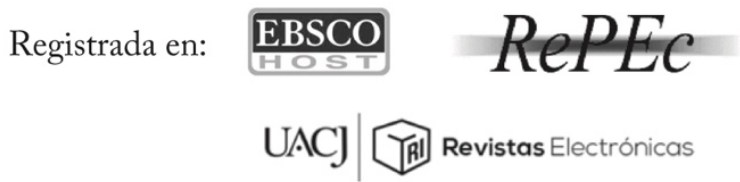

Publicación afiliada a la Red Iberoamericana de Estudios del Desarrollo

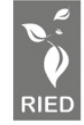

Universidad Autónoma de Ciudad Juárez

Ave Plutarco Elías Calles 1210

Foviste Chamizal, C.P. 32310

Ciudad Juárez, Chihuahua, México

www.uacj.mx

(C) Universidad Autónoma de Ciudad Juárez 
Estudios Regionales en Economía, Población y Desarrollo. Cuadernos de Trabajo, Universidad Autónoma de Ciudad Juárez, publicación afiliada a la Red Iberoamericana de Estudios del Desarrollo, número 64, julio - agosto de 2021, ISSN 2007-3739, pp. 3-34México.

\title{
Isotopías de sostenibilidad urbana y regional en el Estado de México
}

\author{
María Estela Orozco-Hernández *
}

\begin{abstract}
Resumen
Este ensayo explora la instrumentalización de la sostenibilidad urbana y regional en el Estado de México. Por medio de datos institucionales, cuadros, gráficas, mapas y literatura se analizan los instrumentos de planeación, el perfil de los gobiernos municipales en materia de planeación, desarrollo urbano y ordenamiento territorial, el índice de prosperidad y el estado ambiental urbano. La retórica, más allá de un período de gobierno, replantea el paradigma socio organizativo y procesual inherentes al sistema de gestión pública entendido como un proceso coadyuvante en la creación de oportunidades y capacidades para el desarrollo territorial. El marco jurídico vinculante constituye un componente transversal en la medida que establece mecanismos para potencializar y fortalecer las aptitudes de interlocución, negociación y toma de decisiones de los gobiernos municipales, y garantice la inclusión de los avances y retrocesos que retroalimenten los instrumentos de planeación y políticas públicas incluyentes de las dimensiones de la sostenibilidad urbana y regional.
\end{abstract}

Palabras clave: Isotopías, gestión, regionalización, políticas, desarrollo sostenible.

\begin{abstract}
This essay explores the implementation of urban and regional sustainability in the federal State of Mexico. Through institutional data, tables, graphs, maps and literature, we analyze planning instruments, the profile of municipal governments in planning, urban development and land use planning, the prosperity index, and the urban environmental status. The rhetoric beyond a period of government rethinks the socioorganizational and procedural paradigm inherent in the public management system, understood as a contributing process in the creation of opportunities and capacities for territorial development. The binding legal framework constitutes a crosscutting component to the extent that it establishes mechanisms to enhance and strengthen the capacities of dialogue, negotiation, and decision-making of municipal governments, and guarantee the inclusion of advances and setbacks that provide feedback to planning instruments and inclusive policies of the dimensions of urban and regional sustainability.
\end{abstract}

Keywords: Isotopies, management, regionalization, policies, sustainable development.

JEL: $Q 58, R 11, R 58$.

Recibido en: Marzo de 2021.

Aprobado en: Junio de 2021.

* Investigadora adscrita al Centro de Investigación de Estudios Avanzados en Planeación Territorial en la Facultad de Planeación Urbana y Regional de la Universidad Autónoma del Estado de México. Integrante del Cuerpo Académico de Estudios Territoriales y Ambientales. Correo electrónico: meorozcoh@uaemex.mx. ORCID: 0000-0003-4816-7742. 


\section{$\Rightarrow$ 1. Introducción. ${ }^{1}$}

La exploración de la sostenibilidad urbana y regional en el Estado de México retoma la isotopía categoría semántica retórica que da homogeneidad al significado, descripción e interpretación de un discurso (Cárdenas, 2006:121). Parales et al (2007) señalan que la estructuración de los discursos sobre objetos y eventos de controversia pública; incorporan datos de los sistemas de creencias y le dan significación al sistema representacional. Matus (2015) precisa todo discurso constituye una representación de los imaginarios que contextualizan la experiencia social, las isotopías otorgan significado a las visiones políticas, algunas se construyen desde una isotopía de la inclusión "Todos con", otras desde una posibilidad "Sí se puede".

En los últimos veinte años las isotopías de los gobiernos estatales: gobierno que avanza (2001-2005), compromiso, gobierno que cumple (2005-2011), gobierno que trabaja y logra en grande (2011-2017), decisiones firmes, resultados fuertes (2017-2023), delinean el pensamiento, la visión y el proyecto que da sentido a la reconstitución de la gobernabilidad a través de la consecución de los resultados.

Las isotopías de los gobiernos locales 2018-2021, entre otros: Chimalhuacán. Lucha, trabajo y progreso para ti (PRI); San José del Rincón. Juntos definimos el rumbo (PRI); Huixquilucan. Sigamos creciendo (PAN); Naucalpan. Construyendo confianza (PAN); Nezahualcóyotl. Ciudad de todos (PRD); Tlalnepantla. Nuestra ciudad (PRD); Tultitlán. Gobierno del bienestar (Morena); Toluca. Capital (Morena); Ocuilan. Te va a encantar (PAN), evocan visiones particulares y expresan la segmentación del régimen político.

El régimen político conforma las instituciones y normas que regulan los procesos del poder público para tomar decisiones; la gobernabilidad o capacidad de gobernar identifica al gobierno y sus componentes esenciales para la función gubernamental (acciones), lo cual implica relación estrecha entre la política y las políticas públicas (Montero, 2012:10).

La política es un concepto amplio, relativo al poder en general se refiere a la aptitud institucional y legal del aparato gubernamental para crear políticas públicas correspondientes a soluciones específicas para manejar los asuntos públicos (Lahera, 2004:7). En el proceso de formulación de políticas públicas la forma de organización de los actores que intervienen en niveles, con intereses y recursos diversos, podrían no tener correspondencia con las instituciones del régimen

\footnotetext{
${ }^{1}$ Agradezco el apoyo de la Universidad Autónoma del Estado de México y del Consejo Nacional de Ciencia y Tecnología.
} 
político. Para diferenciar los casos presentes en la relación régimen político y regímenes de políticas públicas se requiere de la categoría de gobernabilidad (Montero, 2012:10).

Rivas (2012:328) distingue la gobernabilidad como una situación en la que prevalecen las condiciones favorables para la acción del gobierno, los componentes principales son: la legitimidad y la eficacia. Añade que la gobernabilidad o en su caso la ingobernabilidad son situaciones que favorecen o dificultan la acción del gobierno, la situación de que se trate, no solo es resultado de la política de un gobierno anterior, sino del estilo de la persona que lidera el gobierno.

Delgado (2004:7) considera el liderazgo político como un proceso que integra entre otros componentes, la personalidad, el pensamiento, el proyecto, la agenda y la acción política. Rivas (2012) adiciona la visión, la conducta y la red de apoyos: carrera política, valores, relaciones políticas y sociales y las políticas públicas que se impulsan. González (2013:.246) apunta las políticas públicas que se centran en finalidades, impactos y resultados favorecen la adecuación de nuevos enfoques de política pública que revitalizan al Estado y sus órganos de poder. Las opciones develan la gobernanza como modelo de gestión que legitima procesos de interlocución entre los actores para lograr trabajo coordinado y los resultados esperados

Barros (2009: 154) sostiene que la eficiencia y la eficacia de la gobernanza y los sistemas de administración pública son vitales para un nuevo paradigma de desarrollo. Implica proporcionar alternativas, reducir costos, estimular la eficiencia, acceso ciudadano a la información y participación en las decisiones.

Penagos (2008: 13-28) advierte la disminución del control político de los líderes ejecutivos, los líderes administrativos y técnicos fortalecen su posición debido a la autonomía gerencial que orienta la búsqueda de resultados concretos. La gobernabilidad connota la eficiencia, la eficacia y la transparencia pública. Asimismo, funcionarios que asumen responsabilidades y rinden cuentas a los ciudadanos emergen como símbolos de gobernabilidad. Aunque el marco jurídico-administrativo cuenta con bases generales que posibilitan la planeación y proyección de objetivos y metas, no se ha alcanzado integralidad debido a la carencia de mecanismos que articulen los objetivos estratégicos y desarrollo de los procesos. Se mantienen pautas incrementales en ellas la agregación de metas es un ejercicio de adición de recursos, sin evaluación de los resultados y adecuaciones que reconozcan la dimensión de las desviaciones que resultan de la implementación.

González $(2008: 43,47)$ observa que las dependencias gubernamentales siguen concibiendo la evaluación como tema de control legal, apunta debilidades en la integración vertical y horizontal, la implementación de instrumentos de evaluación no ha sido acompañados de ordenamientos legales para asegurar el aprendizaje organizacional y uso de la información generada en las evaluaciones. 
Arellano y Cabrero (2005: 615) señalan que, para organizaciones gubernamentales eficientes, no es suficiente el gerencialismo, más se requiere un diseño político inteligente y consciente de los aspectos de justicia. Cabrero (2009:15) afirma que los ayuntamientos carecen de competencias constitucionales para promover el desarrollo económico y no están preparados para un manejo gerencial, debido a la escasa profesionalización de los servidores públicos. Garza (2010:492) aclara que los gobiernos locales no requieren de un mandato superior para establecer políticas y estrategias de desarrollo, pero en términos generales carecen de capacidad técnica y financiera para hacerlo.

Cardozo (2013) y González (2013) coinciden en la cooperación y fomento de las capacidades de autogestión bajo el entendido de que la organización y la gestión pública trasciende la estructuración de las políticas públicas para concretar la institucionalidad territorial, resolver las necesidades de la población, prevenir y mitigar las afectaciones ambientales.

La agenda 2030 y la nueva agenda urbana reivindican el desarrollo sostenible y las capacidades para adaptarse a los cambios (ONU, 2016). Rathe (2017) describe la sostenibilidad como la capacidad para crear, probar y mantener aptitudes adaptativas y el desarrollo del proceso de creación, prueba y mantenimiento de las oportunidades. El objetivo del desarrollo sostenible es fomentar la capacidad de adaptación, creando oportunidades y la gestión debe permitir construir y mantener la resiliencia ecológica y social para hacer frente, innovar y adaptarse.

Lezama y Domínguez $(2006: 154,160)$ indican que el significado social de la sustentabilidad es variable de acuerdo con el entorno urbano al que se aplica, no existe un tipo ideal de ciudad sostenible, cada ciudad se conforma por características ambientales, sociales, económicas propias. La sustentabilidad urbana se comprende como un proceso que implica cambios estructurales en las instituciones, en los valores y pautas de conducta social para proveer acceso equitativo a la riqueza natural y socialmente generada.

Métodos y materiales

En el estudio se desarrolló un procedimiento deductivo basado en la información institucional y la literatura. Se partió de los instrumentos de gestión pública y preguntas guía: ¿Qué hacen gobiernos locales, planeación, desarrollo urbano y ordenamiento territorial? ¿Cuál es el lugar de la sostenibilidad urbana? ¿Cuál es el estado ambiental urbano? Se caracteriza el perfil de las acciones que realizan las administraciones municipales, para discernir los cuestionamientos se analiza el índice de prosperidad urbana, productividad y sostenibilidad ambiental y el estado medioambiental situando los factores de las sociedades de consumo: la aglomeración demográfica, contaminación atmosférica, residuos sólidos, fuentes y servicios de provisión de agua. 


\section{Instrumentos de política pública.}

Lopera (2014: 29) sitúa los aspectos políticos que determinan los procesos de planeación que se desprenden del tipo de Estado (universalista/minimalista); el modelo de desarrollo (socialista/capitalista en distintas vertientes), el régimen político (democrático/centralizado) y relaciones entre los actores con grado de intervención distinta. Según el contexto la planeación se reconoce como una política económica y social o un proceso técnico que sistematiza la toma de decisiones.

La carta magna establece atribuciones y responsabilidades del Estado en la coordinación, regulación y fomento a las actividades de interés general, mediante el sistema de planeación democrática. La Ley de Planeación determina la planeación como herramienta para el desempeño de las responsabilidades de los gobiernos nacional, estatal y municipal y mecanismo para dotar de viabilidad a las políticas públicas. La planeación se describe como un proceso técnico racional y sistemático de acciones, fijando objetivos, metas, estrategias y prioridades, incorporando criterios de factibilidad cultural, asignación de recurso, responsabilidades, tiempos de ejecución, coordinación y evaluación de resultados en observación de las disposiciones federales, estatales y municipales. Lahera (2004) señala que, el contenido y la directriz que se despliega en los planes nacionales y sectoriales de desarrollo, los proyectos y los programas estatales para la puesta en marcha de las políticas públicas constituyen factores críticos del éxito.

La Ley de Planeación del Estado de México y Municipios dispone en el sistema de planeación democrática, involucrar a los habitantes, organizaciones sociales y privadas en la elaboración, ejecución y evaluación del Plan Estatal de Desarrollo y los planes municipales. Por medio de la formulación, instrumentación, colaboración, concertación, control, seguimiento de la ejecución y evaluación de las estrategias de desarrollo. El sistema de planeación jerarquiza el plan estatal, los planes municipales, programas de corto, mediano y largo plazo (sectoriales y regionales), programas especiales, presupuesto por programa, convenios (coordinación y participación), informes de evaluación, dictámenes de reconducción y actualización, planes de desarrollo a largo plazo y la agenda digital (GEM, 2001:5-10).

El Plan Estatal de Desarrollo 2017-2023 se alinea a los objetivos de desarrollo sostenible de la agenda 2030. El compromiso plantea seguridad, justicia, modernización y los pilares de desarrollo social, económico, territorial y seguridad, mediante programas de nueva generación se disminuirá la desigualdad, impulsará la vocación regional para el empleo, creación de comunidades sustentables y resilientes, y transformación de la policía y el sistema de justicia. Se asume la responsabilidad de vigilar la preservación de los servicios que el medio ambiente brinda al desarrollo de las actividades 
productivas, control de la erosión de los suelos y las emisiones de contaminantes, manejo adecuado de los residuos sólido, promoción y consumo de bienes y servicios sustentables (GEM, 2018: 32, $155)$.

En el año 2017 se modifica el Plan Estatal de Desarrollo Urbano (PEDU) se incorporan las premisas de la Nueva Agenda Urbana (ONU-HÁBITAT, 2016) y la Nueva Ley General de Asentamientos Humanos, Ordenamiento Territorial y Desarrollo Urbano (SEDATU, 2016). Las inercias mantienen la regionalización del sistema urbano. Valle Cuautitlán-Texcoco (59); Valle de Toluca (22); Atlacomulco (16); Valle de Bravo (9); Tejupilco (6); Ixtapan de la Sal (13) (GEM, 2019:3).

La Nueva Ley General de Asentamientos Humanos, Ordenamiento Territorial y Desarrollo Urbano dispone controlar la expansión urbana y consolidar las ciudades, mediante la coordinación intergubernamental y facultades de los municipios para determinar provisiones, reservas, usos del suelo, crear instrumentos que garanticen la corresponsabilidad institucional y ciudadana para evaluar los resultados (DOF, 2016:1, 2). La nueva agenda urbana suscribe no dejar a nadie atrás, economías urbanas sostenibles e inclusivas. La sostenibilidad ambiental centra la capacidad de adaptación de las ciudades frente al cambio climático, uso adecuado del agua, mitigación de la contaminación ambiental, manejo de desechos, universalización de los servicios públicos y vivienda adecuada, mediante los instrumentos de planeación y las políticas públicas (ONU, 2017:VI).

Tiene prioridad el enfoque administrativo a través de las disposiciones del libro Quinto del Ordenamiento Territorial de los Asentamientos Humanos y del Desarrollo Urbano de los Centros de Población del Código Administrativo del Estado de México. El cual determina los criterios de planeación, ordenación, regulación, control, vigilancia y fomento del ordenamiento territorial de los asentamientos humanos y el desarrollo urbano de los centros de población y la procuración del desarrollo urbano sustentable.

Previo a la modificación del PDU se delimitaron veinte regiones a través de criterios de integridad municipal, continuidad geográfica, vocación económica y social y la división equitativa de la población. Deberán considerarse en la elaboración de los programas de desarrollo regional, a fin de constituir instrumentos de planeación más cercanos a la población, conteniendo la política que seguirá la administración pública en la entidad (GEM, 2018) (Mapa 1).

Gasca (2009) explica que las tareas vinculadas a la política pública incluyen la regionalización, la planeación, los sistemas urbanos regionales, las relaciones intergubernamentales y la gobernanza para los fines del desarrollo y gestión territorial. En síntesis, las regiones plan o programa o programa delimitan los ámbitos de intervención y gestión pública por parte de actores gubernamentales, buscan la coherencia entre el área a considerar y la estructura institucional, 
programática o financiera, pretende alcanzar eficiencia en los planes, programas, proyectos o el ejercicio del gasto público.

Gutiérrez et al (2017: 334-349) indican que los planes, programas o proyectos son instrumentos que resuelven los fines y las funciones de las políticas públicas, pero no toda intervención es política pública, si los instrumentos de planeación no son convergentes, las acciones tampoco. La gestión territorial de la política pública entrama una concatenación económica, políticoadministrativa, sociocultural, institucional y técnico-productiva en el proceso de concertación y liderazgo de los actores. La evaluación mostrará qué tanto las políticas públicas permean la planeación y los resultados.

\section{Mapa 1 \\ División regional de municipios}

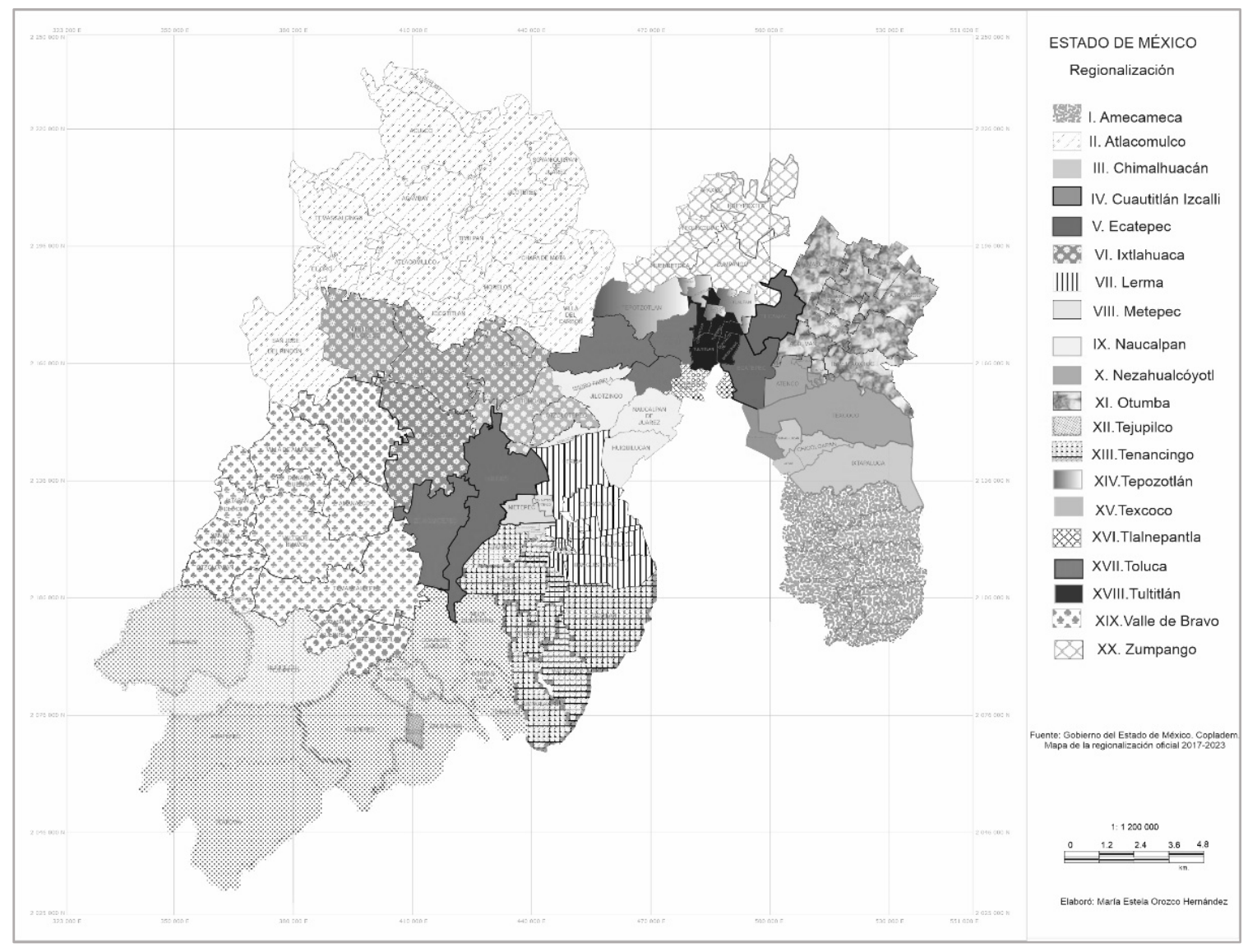

Fuente: Elaboración propia con base en COPLADEM, Gobierno del Estado de México, 2017-2013. 
Las demarcaciones territoriales con fines de administración pública y objetivos de gobierno, remite a la delimitación del valle de Cuautitlán-Texcoco, agrupa cincuenta y nueve municipios articulados a la zona metropolitana de la ciudad de México, el valle de Toluca con veintidós municipios que forman la zona metropolitana de la ciudad de Toluca. El valle Cuautitlán-Texcoco configura 12 regiones programa, el valle de Toluca tres con 13 municipios, nueve se adicionan a las regiones Ixtlahuaca (Otzolotepec, Almoloya de Juárez, Temoaya); Naucalpan de Juárez (Xonacatlán); Tenancingo (Tenango del Valle, Almoloya del Río, Calimaya, Rayón, San Antonio la Isla). Ixtapan de la Sal (Cuadro 1).

El PEDU suscribe revisar las estrategias de ordenamiento territorial para las acciones y programas gubernamentales y de los sectores social y privado en los aspectos que inciden en el desarrollo regional y urbano. Vinculación con el Plan Estatal de Desarrollo en los pilares social, económico y territorial. Soporte técnico para la determinación de las políticas públicas urbanas y territoriales. Determinación de estrategias, lineamientos de programas, proyectos y acciones de desarrollo urbano y ordenamiento territorial que se aplicarán en la entidad, bajo criterios de concertación con los sectores público, privado y social. Soluciones en materia de movilidad, espacio público, suelo y vivienda, equipamiento, agua y saneamiento, riesgos naturales, el modelo de gestión, financiamiento e inversión, así como lineamientos para que los municipios instrumenten las estrategias con las herramientas de los sistemas de información geográfica.

Cuadro 1

Estado de México: regiones urbanas y regiones plan

\begin{tabular}{|l|c|l|c|}
\hline $\begin{array}{l}\text { I. VALLE CUAUTITLÁN - } \\
\text { TEXCOCO }\end{array}$ & 59 & \multicolumn{1}{|c|}{ II. VALLE DE TOLUCA } & 22 \\
\hline Regiones político-administrativas & No. de municipios & Regiones político-administrativas & No. de municipios \\
\hline V. Ecatepec & 2 & XVII. Toluca & 2 \\
\hline III. Chimalhuacán & 4 & VIII. Metepec & 4 \\
\hline IV. Cuautitlán Izcalli & 3 & VII. Lerma & 7 \\
\hline IX. Naucalpan & 5 & III. ATLACOMULCO & 16 \\
\hline X. Nezahualcóyotl & 1 & II. Atlacomulco & 14 \\
\hline I. Amecameca & 13 & VI. Ixtlahuaca & 6 \\
\hline XVIII. Tultitlán & 4 & IV. VALLE DE BRAVO & 19 \\
\hline XVI. Tlalnepantla & 1 & XIX. Valle de Bravo & 12 \\
\hline XV. Texcoco & 4 & V. TEJUPILCO & 6 \\
\hline XI. Otumba & 10 & XII. Tejupilco & 11 \\
\hline XX. Zumpango & 5 & VI. IXTAPAN DE LA SAL & 13 \\
\hline XIV. Tepotzotlán & 7 & XIII. Tenancingo & 10 \\
\hline \multicolumn{1}{|c|}{12} & 59 & 8 & 66 \\
\hline
\end{tabular}

Fuente: Elaboración propia con base en: GEM, 2018; GEM, 2019. 


\section{1. ¿Qué hacen gobiernos locales planeación, desarrollo urbano y ordenamiento territorial?}

El perfil de 125 municipios, indica que $71.2 \%$ realiza planeación urbana, 82.4\% ejecuta desarrollo urbano y $63.2 \%$ ordenamiento territorial. 118 gobiernos locales o $23 \%$ implementa programas federales o estatales para desarrollo urbano (PEDU; 2008:16, INEGI, 2017), (Gráfica 1).

Gráfica 1

\section{Municipios con actividades de planeación, desarrollo urbano y ordenamiento territorial}

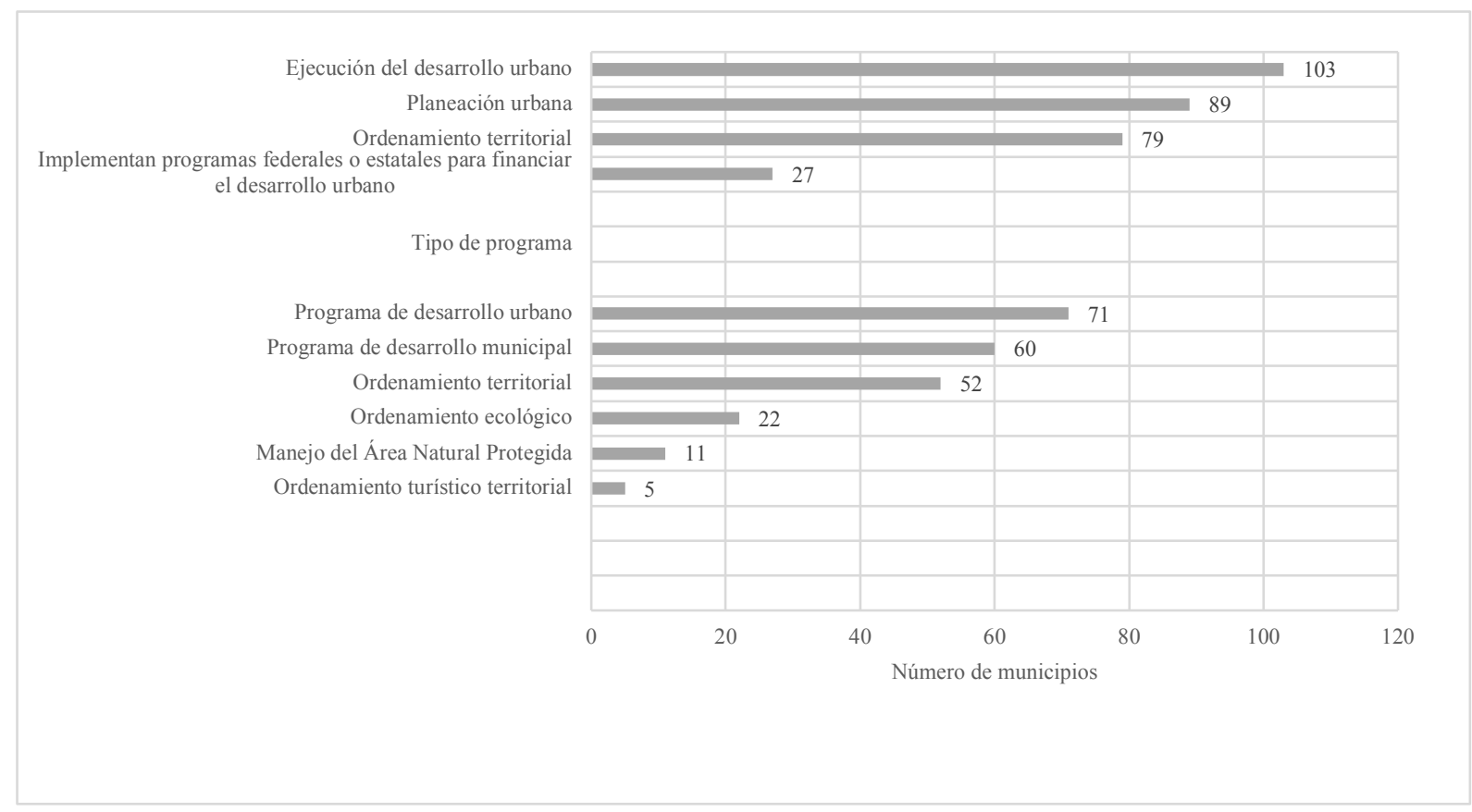

Fuente: Elaboración propia INEGI, 2017.

La tipología de programas muestra disimilitudes debido a que las administraciones reportan más de un programa o acción, $60 \%$ cuentan con programa de desarrollo urbano; $51 \%$ programa de desarrollo municipal y 44\% con programa de ordenamiento territorial. En menor proporción programas de ordenamiento ecológico, manejo de áreas naturales protegidas y ordenamiento turístico territorial. Menos de la mitad de los gobiernos locales (38\%) planifica o registra reservas territoriales y destino potencial: industrial, equipamiento y habitacional (Gráfica 2).

Asentamientos irregulares y asentamientos en zonas de riesgo en más de $50 \%$ de los municipios, 40\% realiza acciones de prevención, pocas acciones de difusión y comunicación, delimitación física, clausura, sanción o denuncia y desalojo (Gráfica 3). 


\section{Municipios que planifican reservas territoriales y usos potenciales}

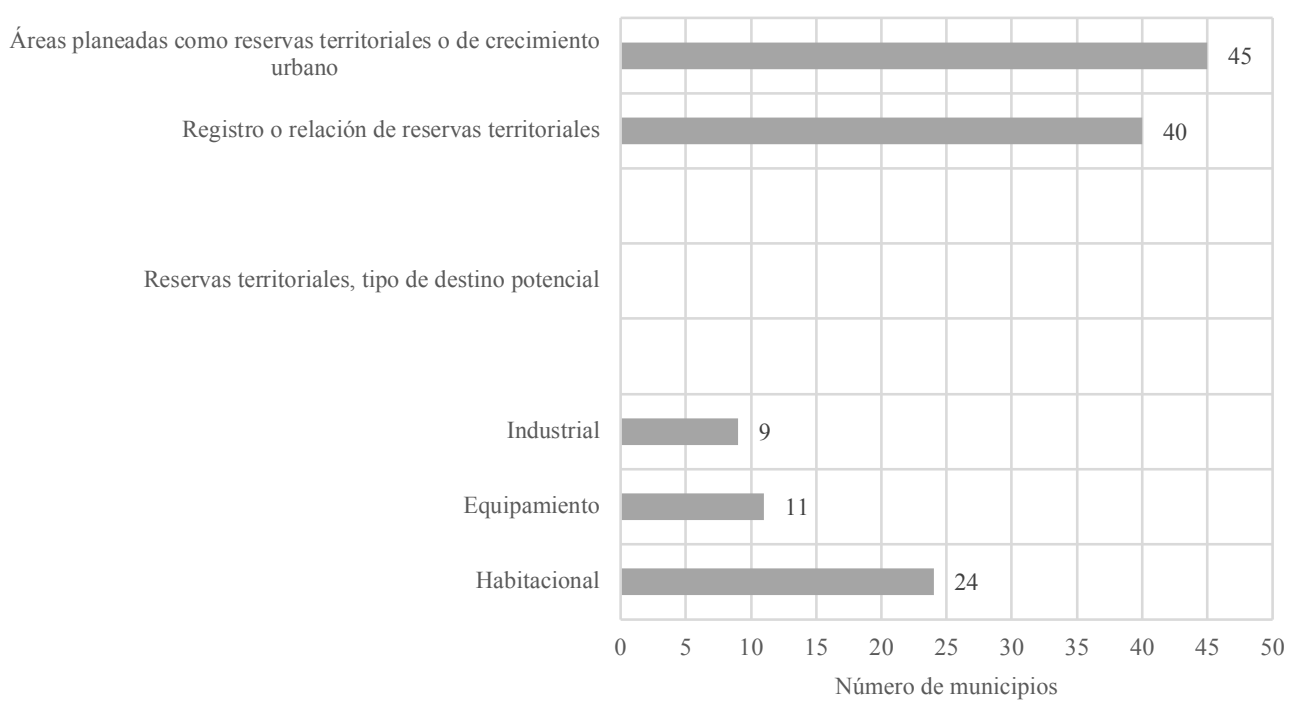

Fuente: Elaboración propia INEGI, 2017.

Gráfica 3

Municipios con asentamientos irregulares, en zonas de riesgo y acciones de prevención

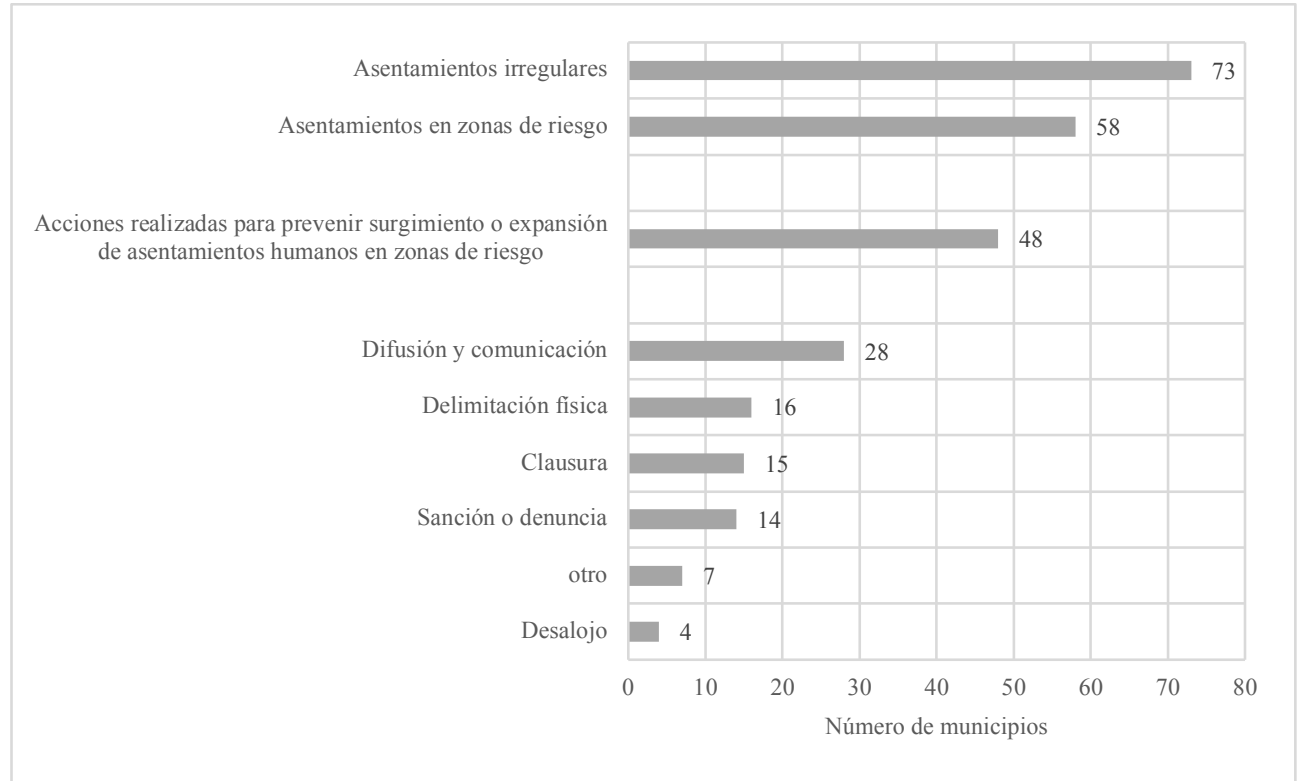

Fuente: Elaboración propia INEGI, 2017. 
Poco más de la mitad realiza acciones en coordinación con instancias de administración estatal. Un tercio reduce la ocupación irregular de predios, implementa mecanismos para reubicar o regularizar asentamientos informales (Gráfica 4).

\section{Municipios que realizan acciones de control de uso de suelo}

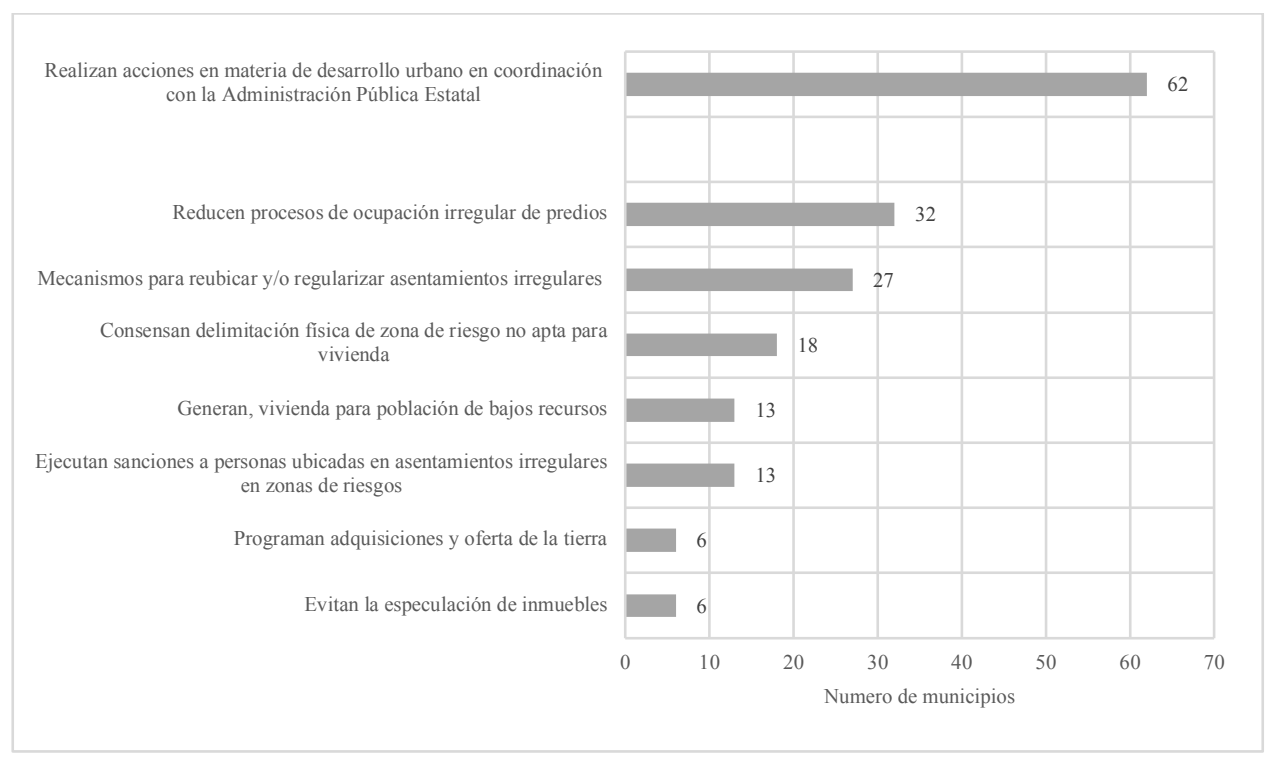

Fuente: Elaboración propia INEGI, 2017.

Pocos municipios consensan delimitación de zonas de riesgo, promueven vivienda para población de bajos recursos, sancionan a los ocupantes de asentamientos irregulares en zonas de riesgo, programan oferta y adquisiciones de tierra y evitan la especulación inmobiliaria. Los municipios con planificación y acciones de desarrollo sustentable 22\%, implementación de acciones en la estrategia de ciudad compacta 19\%, aprovechamiento de predios baldíos 12\% (Gráfico 5).

Resaltan las acciones de regulación de los usos de suelo, mejora de la imagen urbana, uso del espacio intraurbano, apenas mención de acciones que impulsen el desarrollo urbano sostenible. 


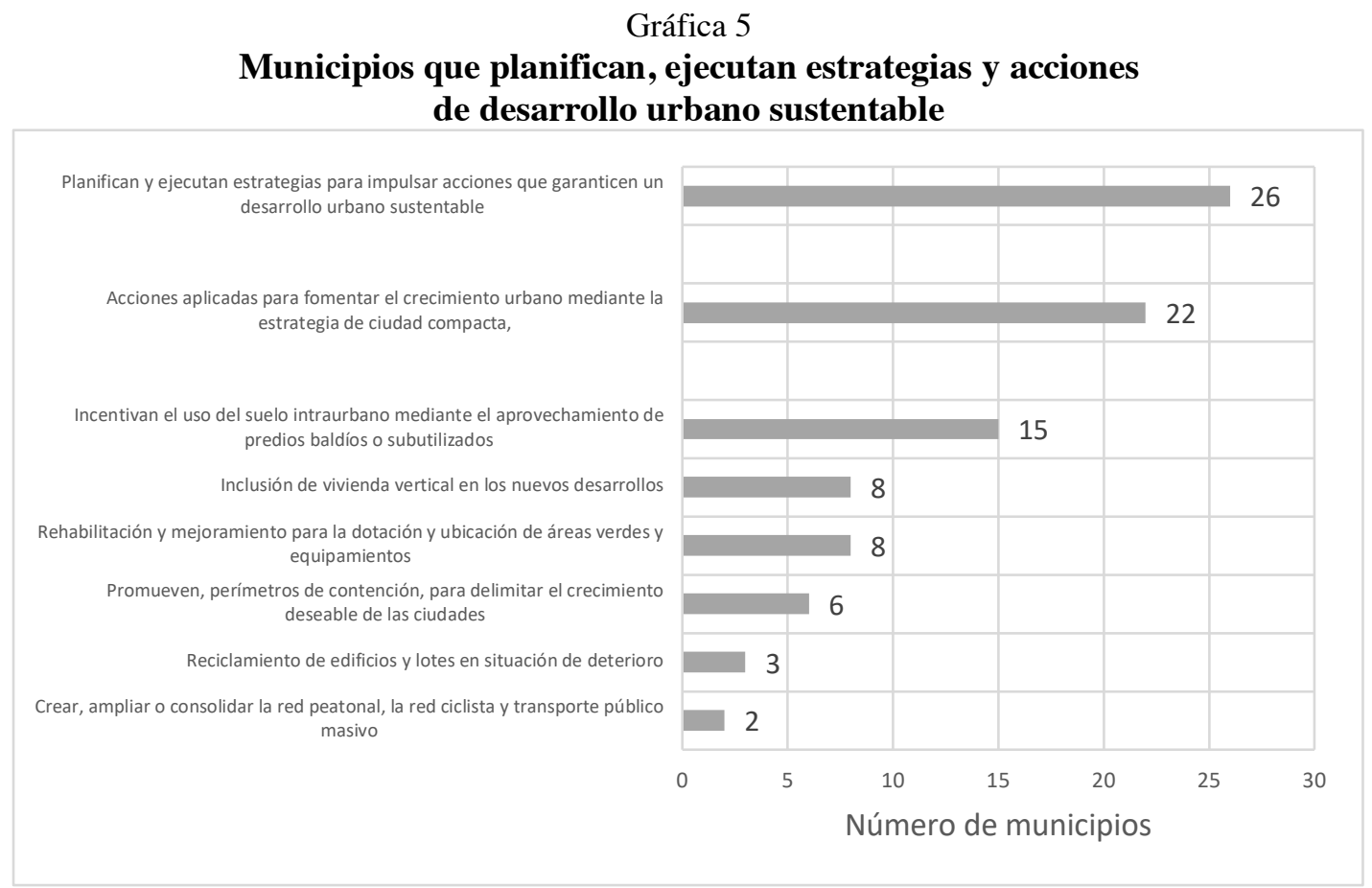

Fuente: Elaboración propia INEGI, 2017.

\section{2. ¿Cuál es el lugar de la sostenibilidad urbana?}

Barreto-Villanueva (2012: 29) señala que la integración en las estadísticas de conceptos ambientales, económicos, sociales, culturales y políticos es importante para determinar la prosperidad de una comunidad. Sin embargo, el problema es cómo hacer representativas las estadísticas para que reflejen la prosperidad y el bienestar como fenómenos multidimensionales. La cuestión remite al índice de ciudades prosperas (ICP) el cual oferta una radiografía de la complejidad urbana a través de una métrica que mide el bienestar, la eficiencia de la ciudad y el efecto de las políticas públicas (ONU-HÁBITAT, 2019).

La versión nacional del índice de prosperidad coloca en el centro la función instrumental de la ciudad como lugar privilegiado en donde los seres humanos logran sus aspiraciones intangibles y bienestar, acceden a bienes y servicios suficientes y cuentan con servicios públicos esenciales (ONUHABITAT, 2016). El cálculo del ICP se realizó en tres escenarios: básico, extendido y contextual en los que se consideran las dimensiones siguientes: productividad, infraestructura de desarrollo; calidad 
de vida; equidad e inclusión social; sostenibilidad ambiental ${ }^{2}$, gobernanza y legislación urbana. La valoración establece tres escalas de prosperidad y tres niveles de intervención (Cuadro 2).

Cuadro 2

Valores de las dimensiones de ciudades prosperas

\begin{tabular}{|l|l|l|}
\hline Valores del ICP & Escalas de prosperidad & Niveles de intervención \\
\hline $80-100$ & Muy sólidos & Consolidar políticas urbanas \\
$70-79$ & Sólidos & \\
\hline $60-69$ & Moderadamente sólidos & Fortalecer políticas urbanas \\
$50-59$ & Moderadamente débiles & \\
\hline $40-49$ & Débiles & Priorizar políticas urbanas \\
$00-39$ & Muy débiles & \\
\hline
\end{tabular}

Fuente: ONU-HABITAT. 2019: 38.

La media nacional definida de 365 municipios, en los que reside $87 \%$ de la población y se localizan las aglomeraciones más importantes del sistema urbano nacional, reporta un índice de prosperidad de 53.7/100. El índice de las ciudades del país, salvo algunas excepciones, expone debilidad en sostenibilidad ambiental, gobernanza y legislación urbana. Las ciudades de México y Toluca obtuvieron índices de 53.3 y 52, la primera debilidad en infraestructura y desarrollo, ambas debilidades en sostenibilidad ambiental, gobernanza y legislación urbana (Cuadro 3).

Cuadro 3

Comparación del índice de prosperidad

\begin{tabular}{|l|c|c|c|c|c|c|}
\hline & I. Productividad & $\begin{array}{c}\text { II. } \\
\text { Infraestructura y } \\
\text { desarrollo }\end{array}$ & $\begin{array}{c}\text { III. } \\
\text { Calidad } \\
\text { de vida }\end{array}$ & $\begin{array}{c}\text { IV. Equidad } \\
\text { e inclusión } \\
\text { social }\end{array}$ & $\begin{array}{c}\text { V. } \\
\text { Sostenibilidad } \\
\text { ambiental }\end{array}$ & $\begin{array}{c}\text { VI. } \\
\text { Gobernanza } \\
\text { y legislación } \\
\text { urbana }\end{array}$ \\
\hline $\begin{array}{l}\text { Ciudad de } \\
\text { México }\end{array}$ & 65.20 & 66.90 & 68.30 & 73.20 & 39.40 & 33.40 \\
\hline $\begin{array}{l}\text { Ciudad de } \\
\text { Toluca }\end{array}$ & 62.40 & 55.10 & 67.50 & 71.30 & 37.70 & 31.70 \\
\hline
\end{tabular}

Fuente: CESOP, 2018, pág. 18.

2 Sostenibilidad Ambiental: calidad del aire; número de estaciones de monitoreo; concentraciones de material particulado; concentración de $\mathrm{CO} 2$; manejo de residuos; recolección de residuos sólidos; tratamiento de aguas residuales; energía; generación de energía renovable. La Sostenibilidad Ambiental resulta de la medición de la calidad del aire, manejo de residuos y generación de energía renovable. 
En la entidad se determinó el escenario básico ${ }^{3}$ de 54 municipios, cuyo objetivo es brindar a los tomadores de decisiones municipales herramientas para identificar oportunidades y desafíos, desarrollar políticas públicas basadas en evidencias y aportar insumos para informar instrumentos de planeación urbana. Quince municipios obtuvieron un índice menor a cincuenta (27.27\%), con prosperidad muy débil y un nivel intervención que prioriza políticas urbanas (Mapa 2).

\section{Índice de prosperidad por municipio}

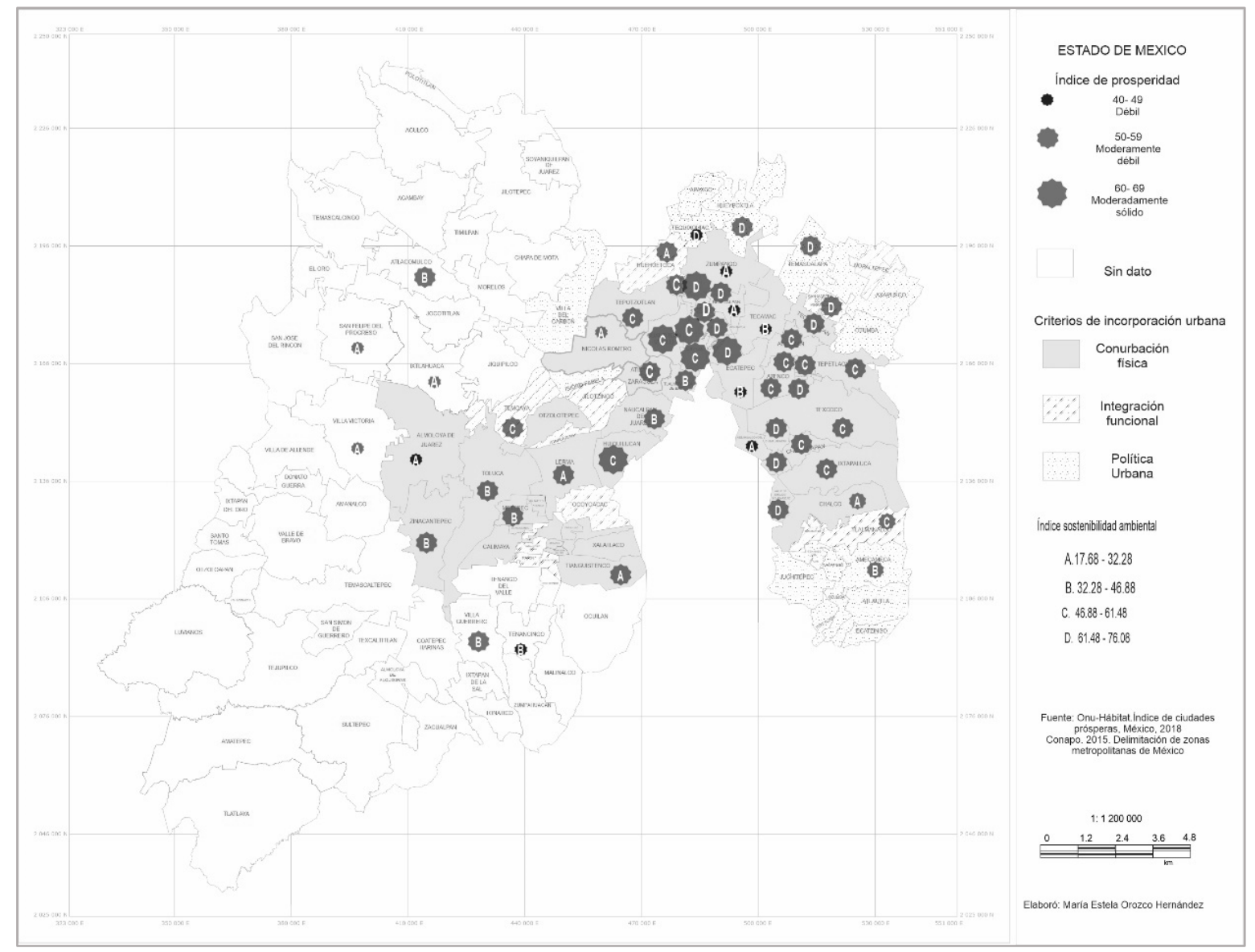

Fuente: Elaboración propia con base en ONU-Hábitat, 2018.

${ }^{3}$ El CPI básico permite la comparación entre ciudades pertenecientes a la misma región o país y cotejo a nivel internacional. Tiene 6 dimensiones, 21 subdimensiones y 40 indicadores. 
Treinta y tres (61.1\%) índices entre 50 y 59, prosperidad moderadamente débil y seis municipios $(11.11 \%)$ índice mayor a 60 prosperidad moderadamente sólida: Cuautitlán, Coacalco, Huixquilucan, Teoloyucan, Cuautitlán Izcalli y Tultitlán. En ambos grupos la intervención establece fortalecer las políticas urbanas. La distribución territorial configura la imagen de la prosperidad moderadamente débil y muy débil, así también vacíos municipales al norte, poniente, sur y contornos de la porción oriente. La sostenibilidad ambiental con índices moderadamente sólidos y solidos en municipios que forman parte del área de influencia de ciudad de México (Gráfica 6).

\section{Gráfica 6}

\section{Comparativo de los índices de productividad y sostenibilidad ambiental regional}
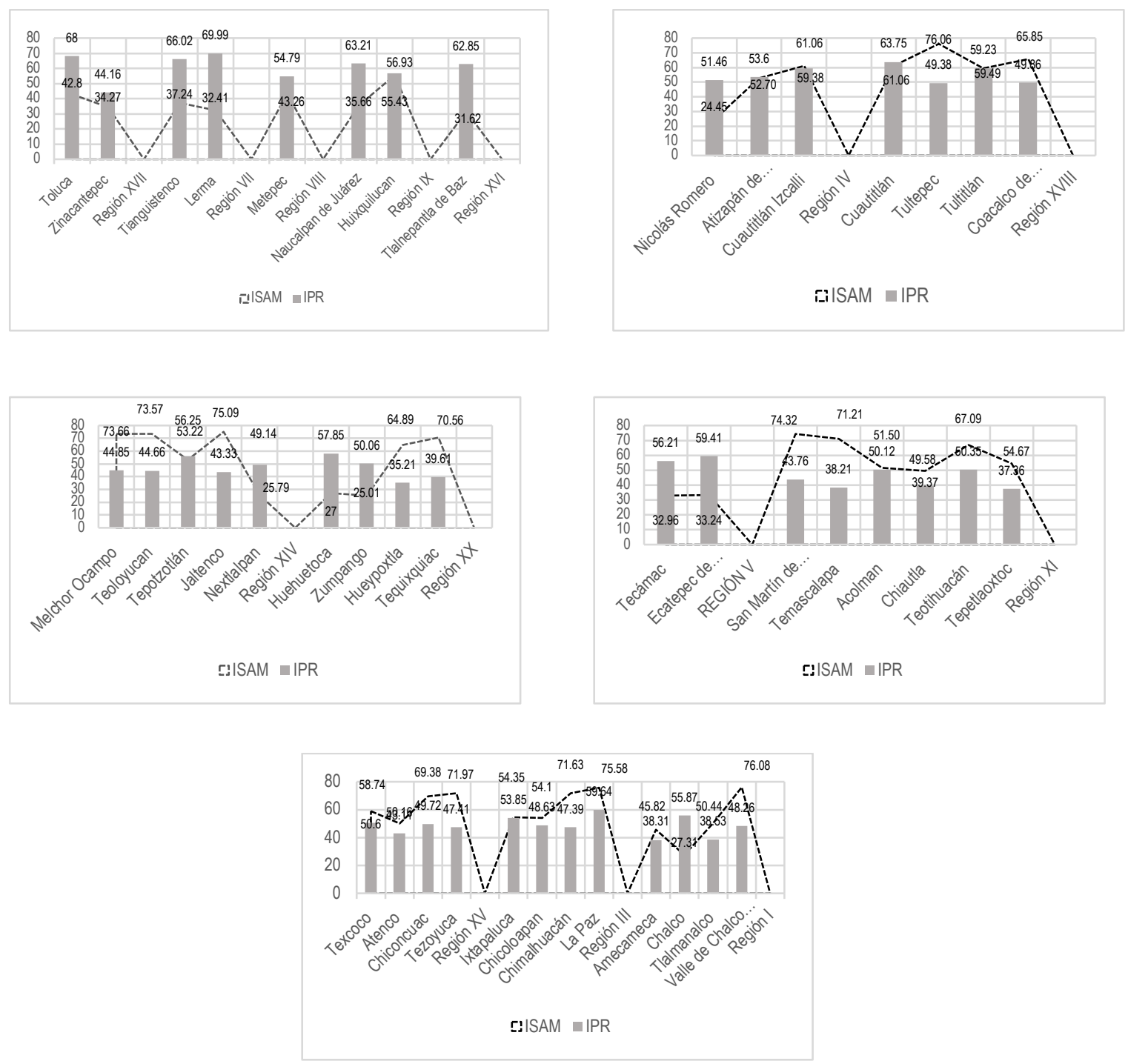

Fuente: Elaboración propia, datos ONU-Hábitat, 2018. 
El índice de sostenibilidad ambiental identifica diecisiete municipios en el intervalo 61.48 a 76.08, en las regiones, Cuautitlán Izcalli, Tultitlán, Zumpango y Otumba. En general los índices altos se deben al peso de la recolección de residuos sólidos, pocos con estaciones de monitoreo y datos de concentración de dióxido de carbono $\left(\mathrm{CO}_{2}\right)$, ausencia de manejo de residuos, tratamiento de aguas residuales, concentraciones de material particulado y generación de energía renovable

Es índice de productividad ${ }^{4}$ superior a 60 corresponde a los nodos de actividad económica, Lerma, Toluca, Tianguistenco, Cuautitlán; Naucalpan de Juárez y Tlalnepantla, en tanto, el índice de sostenibilidad ambiental es débil o muy débil. En el sector de productividad inferior a 50, Valle de Chalco Solidaridad, Tultepec, Jaltenco, San Martín de las Pirámides, Melchor Ocampo, Teoloyucan, Tezoyuca, Chimalhuacán, Temascalapa, Tequixquiac, índices de sostenibilidad ambiental sólido o muy sólido. En general debilidad en la legislación urbana entendida como el conjunto de leyes por medio de las cuales se gobierna o dirige la materia urbana.

\section{3. ¿Cuál es el estado ambiental urbano?}

Lezama y Domínguez (2006: 158) identifican posturas, que interpretan la inclusión de lo ambiental como parte de la estrategia discursiva para enverdecer la acción gubernamental, domina el enfoque económico, la visión instrumental de la planeación y el diseño de las políticas públicas al margen de la sustentabilidad. Si la dimensión ambiental es pieza clave en los procesos de desarrollo regional y urbano y calidad de vida de la población. La aglomeración demográfica desempeña un doble papel, factor de formación regional y factor de presión de los bienes y servicios disponibles. En la medida que crece la población, aumenta la demanda de agua y suelo, la evacuación de desechos y la contaminación.

El proceso demográfico del Estado de México se asocia intrínsicamente al distrito central del país hoy ciudad de México. La retrospectiva situada de 15,175,862 de habitantes (INEGI, 2010), indica que $60.5 \%$ de la población se concentra en las regiones Ecatepec, Chimalhuacán, Cuautitlán Izcalli, Naucalpan, Nezahualcóyotl, Tultitlán y Toluca. La encuesta intercensal reporta 16, 87,608 de habitantes, $87 \%$ población urbana y 13\% rural (INEGI, 2015). La distribución de la población por localidad expone el fenómeno de concentración en localidades urbanas 2,500 a 99,999 habitantes

\footnotetext{
${ }^{4}$ Productividad. El valor es referente del crecimiento de la economía local y posible impacto en la calidad de vida: Crecimiento económico; Producto urbano per cápita; Relación de dependencia de la tercera edad; Aglomeración económica; Densidad económica; Empleo; Tasa de desempleo; Relación empleo-población.
} 
(29\%) y localidades de 100,000 y más habitantes (57\%). La relación población urbana y población total estima índice de urbanización de $21.52 \%{ }^{5}$ (Cuadro 4).

Cuadro 4

Estado de México: rango tamaño de localidad, población y tasa de urbanización

\begin{tabular}{|l|r|r|r|}
\hline \multicolumn{1}{|c|}{ Rango tamaño de localidad } & Población & $\%$ & $\begin{array}{l}\text { Índice o tasa de } \\
\text { urbanización }\end{array}$ \\
\hline Menos de 2 500 habitantes & 2251362 & 14 & na \\
\hline $2500-14999$ habitantes & 2739653 & 17 & 4.23 \\
\hline $15000-49999$ habitantes & 1472667 & 9 & 2.27 \\
\hline $50000-99999$ habitantes & 549900 & 3 & 0.85 \\
\hline 100000 y más habitantes & 9174026 & 57 & 14.17 \\
\hline & 16187608 & 100 & 21.52 \\
\hline
\end{tabular}

Fuente: Elaboración propia, datos de https://www.inegi.org.mx/programas/intercensal/2015/\#Tabulados.

La tendencia demográfica recrea la aglomeración urbana en las regiones Toluca, Metepec y Lerma, siguiendo la ruta Naucalpan, Tlalnepantla, Cuautitlán Izcalli, Tultitlan, Ecatepec, Amecameca y Texcoco. En los contornos municipios de las regiones Zumpango y Otumba, la dispersión y densidad baja propia de las regiones de Atlacomulco, Ixtlahuaca, Valle de Bravo, Tejupilco y Tenancingo. Al norte y oriente de la ciudad de México, Nezahualcóyotl, Chimalhuacán, Ecatepec de Morelos, densidad promedio 15,000 y 20,350 hab/km². Valle de Chalco Solidaridad, Tlalnepantla de Baz, Tultitlán, Coacalco de Berriozábal, La Paz, Jaltenco, Atizapán de Zaragoza, Tultepec y Naucalpan, 6,000 y 12,550 hab/km² (Gráfica 7).

5 Índice de urbanización población en localidades de 2500 habitantes y más, la población total: 1/4* (POBURB/POBTOTAL) $* 100$. 


\section{Gráfica 7 \\ Tendencia demográfica regional 2010-2030}

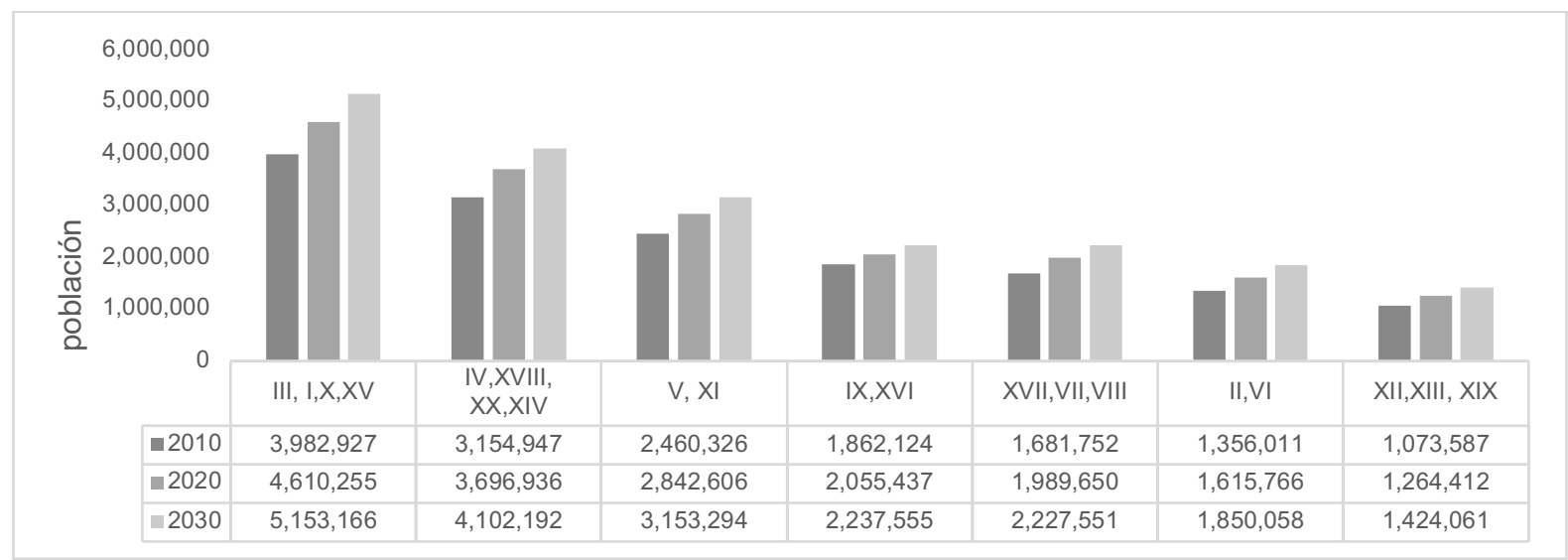

Fuente: Elaboración propia datos de CONAPO, 2015. https://www.inegi.org.mx/programas/ccpv/2010/\#Tabulados.

La aglomeración demográfica y la intensidad de la actividad antropogénica multiplica la contaminación atmosférica y el volumen de residuos sólidos. El control ambiental centra el potencial de contaminación de los vehículos en circulación por la emisión de monóxido y dióxido de carbono debido a la combustión de gasolina y diésel (Gráfica 8).

Gráfica 8

Vehículos en circulación en el Estado de México

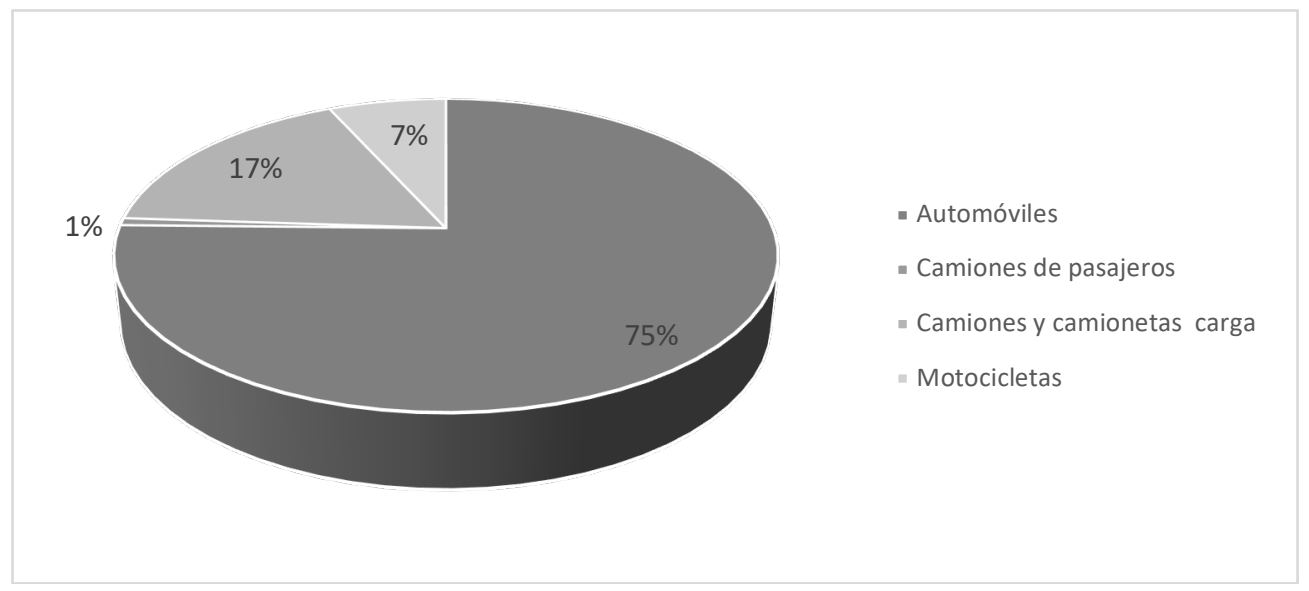

Fuente: Elaboración propia, datos cuadro 22.6 INEGI, 2018. 
El parque vehicular conforma 7,342,919 de vehículos de motor, destaca el automóvil particular, camiones y camionetas de carga, motocicletas en aumento. Los camiones de pasajeros comprenden autobuses urbanos y suburbanos, microbuses, camiones escolares, camionetas pick-up, ómnibus, destinados al transporte público o privado. Las regiones metropolitanas de poniente-oriente aportan $11 \%$ y $77 \%$ de los vehículos en circulación (Cuadro 5).

El monitoreo de calidad del aíre se realiza en estaciones de cobertura regional y el control de las emisiones por medio de la verificación vehicular. La Red Automática de Monitoreo Atmosférico (RAMA) de la ciudad de México consta de 44 estaciones distribuidas en alcaldías y municipios del Estado de México, Acolman, Atizapán de Zaragoza, Chalco, Tepotzotlán, Naucalpan de Juárez, Nezahualcóyotl; Ocoyoacac, Tlalnepantla de Baz (2), Ecatepec de Morelos (3), Texcoco y Coacalco. La Red de Monitoreo Atmosférico de la zona metropolitana de Toluca ocho estaciones (Toluca centro, Oxtotitlán, Ceboruco, Almoloya de Juárez, Metepec, San Mateo Atenco y Xonacatlán). Las concentraciones de dióxido de azufre $\mathrm{SO}$; monóxido de carbono $\mathrm{CO}$; dióxido de nitrógeno $\mathrm{NO} 2$; ozono O3, partículas suspendidas PM10 y PM 2.5, varían al día, hora y época del año, depende de las condiciones atmosféricas y la dinámica citadina. En 2018 se determinó contingencia ambiental en la ciudad de México debido a las concentraciones de ozono y en la ciudad de Toluca la concentración de partículas suspendidas agudiza la contaminación por polvos orgánicos e inorgánicos (PM10 y PM 2.5). En junio 2020 la calidad del aíre en la zona metropolitana de la ciudad de México se reportó buena (GCM, 2020). En el valle de Toluca regular en partículas PM10 y PM 2.5 (73 y 79), la concentración de NO2, CO, SO2 de 0 a 50 determinó buena calidad del aire (GEM, 2020). 


\section{Cuadro 5 \\ Distribución regional de los vehículos en circulación}

\begin{tabular}{|c|c|c|c|c|c|c|}
\hline $\begin{array}{l}\text { Regiones } \\
\text { metropolitanas }\end{array}$ & No. de municipios & Automóviles & $\begin{array}{r}\text { Camiones de } \\
\text { pasajeros }\end{array}$ & $\begin{array}{r}\text { Camiones y } \\
\text { camionetas } \\
\text { para carga }\end{array}$ & Motocicletas & Total \\
\hline V. Ecatepec & 2 & 949,628 & 7,841 & 218,886 & 82,571 & $1,258,926$ \\
\hline III. Chimalhuacán & 4 & 382,824 & 3,715 & 90,067 & 63,520 & 540,126 \\
\hline $\begin{array}{l}\text { IV. Cuautitlán } \\
\text { Izcalli }\end{array}$ & 3 & 603,840 & 5,355 & 92,533 & 42,025 & 743,753 \\
\hline IX. Naucalpan & 5 & 621,771 & 6,785 & 97,109 & 43,037 & 768,702 \\
\hline X. Nezahualcóyotl & 1 & 586,812 & 6,238 & 121,223 & 72,227 & 786,500 \\
\hline I. Amecameca & 13 & 212,329 & 6,710 & 59,796 & 29,130 & 307965 \\
\hline XVIII. Tultitlán & 4 & 412,259 & 3,042 & 77,511 & 36,934 & 529,746 \\
\hline XVI. Tlalnepantla & 1 & 417,692 & 4,557 & 75,175 & 32,858 & 530,282 \\
\hline \multirow[t]{2}{*}{ XV. Texcoco } & 4 & 127,647 & 1,732 & 31,123 & 13,809 & 174,311 \\
\hline & 37 & $4,314,802$ & 45,975 & 863,423 & 416,111 & $5,640,311$ \\
\hline XVII. Toluca & 2 & 383,850 & 4,003 & 84,882 & 25,026 & 497,761 \\
\hline VIII. Metepec & 4 & 149,705 & 70 & 25,085 & 9,740 & 184,600 \\
\hline \multirow[t]{2}{*}{ VII. Lerma } & 7 & 93,179 & 116 & 32,635 & 5,413 & 131,343 \\
\hline & 13 & 626,734 & 4,189 & 142,602 & 40,179 & 813,704 \\
\hline \multicolumn{7}{|l|}{ Regiones hinterland } \\
\hline XI. Otumba & 10 & 102,294 & 511 & 33,241 & 8,140 & 144,186 \\
\hline XX.Zumpango & 5 & 88,946 & 1,409 & 27,850 & 7,437 & 125,642 \\
\hline XIV. Tepotzotlán & 7 & 78,135 & 1,612 & 21,815 & 7,327 & 108,889 \\
\hline & 22 & 269,375 & 3,532 & 82,906 & 22,904 & 378,717 \\
\hline
\end{tabular}

Regiones rural-

urbanas

$\begin{array}{lccccrr}\text { II. Atlacomulco } & 14 & \mathbf{1 0 5 , 6 2 9} & \mathbf{3 2 3} & \mathbf{5 5 , 9 5 2} & \mathbf{3 , 0 2 1} & \mathbf{1 6 4 , 9 2 5} \\ \text { VI. Ixtlahuaca } & 6 & \mathbf{7 7 , 0 3 1} & \mathbf{3 5 4} & \mathbf{3 9 , 8 4 6} & \mathbf{3 , 4 5 1} & 6,472\end{array}$

\begin{tabular}{lcccrrr} 
Regiones rurales & \multicolumn{1}{c}{} & & \\
\hline XII. Tejupilco & 11 & $\mathbf{4 2 , 7 2 6}$ & $\mathbf{3 4}$ & $\mathbf{3 4 , 2 1 7}$ & $\mathbf{4 , 8 4 9}$ & 81,826 \\
$\begin{array}{l}\text { XIII. Tenancingo } \\
\text { XIX. Valle de }\end{array}$ & 10 & $\mathbf{5 4 , 0 3 1}$ & $\mathbf{1 5 6}$ & $\mathbf{2 3 , 2 5 0}$ & $\mathbf{3 , 9 2 9}$ & 81,366 \\
Bravo & 12 & $\mathbf{4 0 , 5 1 1}$ & $\mathbf{5 1}$ & $\mathbf{1 8 , 8 1 3}$ & $\mathbf{2 , 0 1 3}$ & 10,791
\end{tabular}

Fuente: Elaboración propia datos INEGI, 2018.

A partir de febrero 2020 la NOM-172-SEMARNAT-2019 establece el procedimiento de cálculo y difusión del índice de calidad del aire y riesgos a la salud, el nuevo índice sustituye el índice de la calidad del aire (IMECA) y deberá observarse en las zonas metropolitanas, ciudades y municipios con estaciones de monitoreo. 
En materia de residuos sólidos los gobiernos locales proporcionan servicios de recolección y disposición final, la diferencia radica en las fases de transferencia, almacenamiento, traspaso y tratamiento, pocos tienen reglamento y carecen de programa de gestión integral de residuos sólidos. El promedio diario estatal de residuos sólidos urbanos recolectados 12,342 toneladas, la región Ecatepec aporta 28\%; Nezahualcóyotl 10\%, Cuautitlán Izcalli, Tultitlán, Amecameca, 24\%, Naucalpan, Toluca y Tlalnepantla, 17\%, el conjunto 79\% (Mapa 3).

\section{Mapa 3}

\section{Residuos sólidos urbanos recolectados} Promedio diario municipal (Kilogramos)

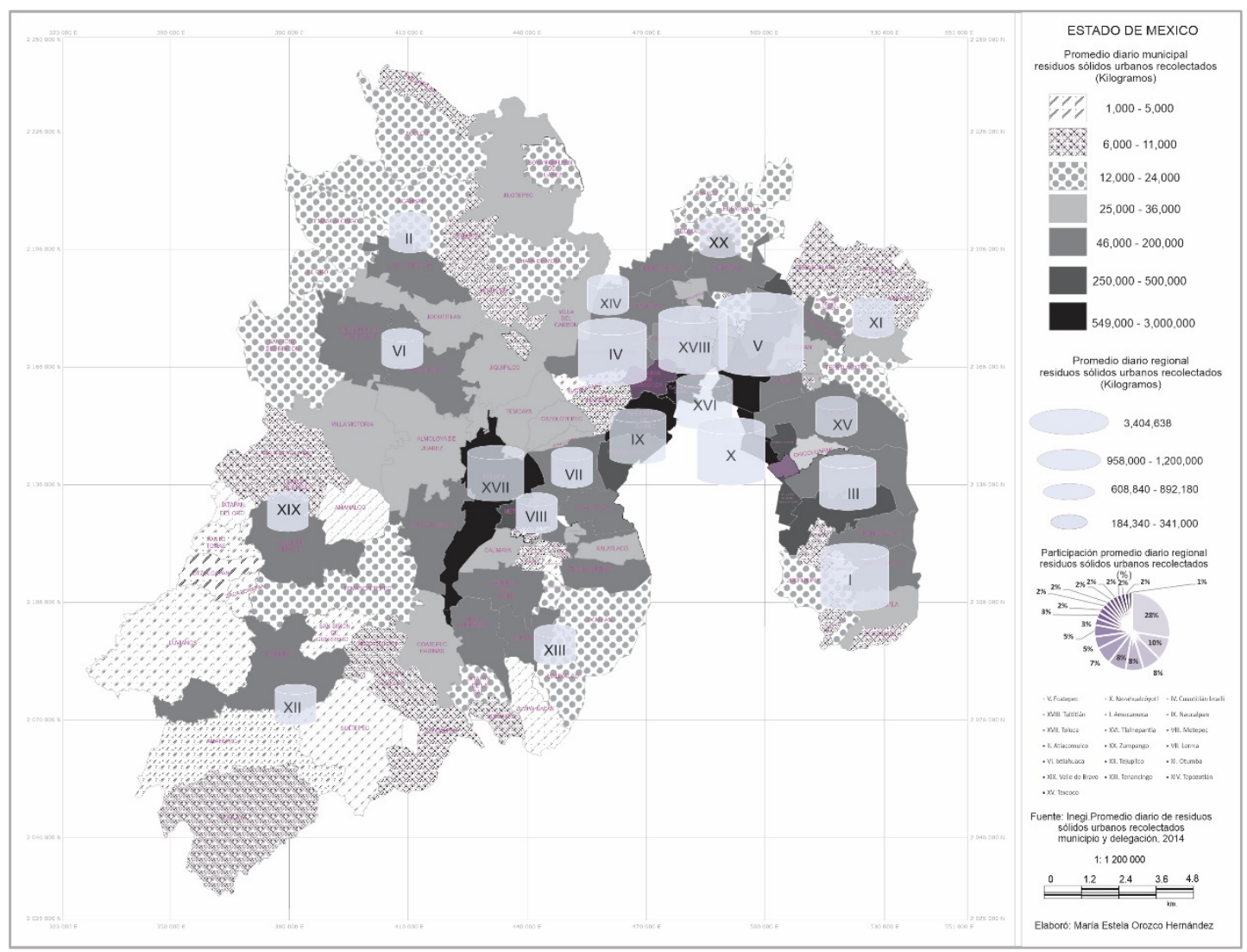

Fuente: Elaboración propia con base en INEGI, 2014.

La recolección se realiza sin selección, no hay participación ciudadana en la gestión de los residuos sólidos, los residuos se recogen casa por casa o en un sitio determinado (85\%), casa por casa y contenedores $(15 \%)$. La eliminación de residuos producidos en las viviendas particulares habitadas 
$(4,166,570)$, consiste en la entrega al servicio público, $90.56 \%$, quema $(5.91 \%)$, tirar en basurero (2.62\%), enterrar o tirar (0.31\%) (INEGI, 2015) (Cuadro 6).

El servicio de recolección se provee a través de un número variable de vehículos, depende del área de servicio en asentamientos urbanos. La dispersión de asentamientos rurales eleva los costos de operación, ocasiona carencia de servicio o es itinerante y deficiente (Cuadro 6).

\section{Cuadro 6}

\section{Porcentaje de viviendas habitadas entregan residuos a servicio público} 2015

\begin{tabular}{|c|c|c|c|c|c|c|c|}
\hline $\begin{array}{l}\text { Regiones } \\
\text { metropolitanas }\end{array}$ & $\begin{array}{l}\text { Viviendas } \\
\text { habitadas }\end{array}$ & $\begin{array}{l}\text { \%Entregan } \\
\text { servicio } \\
\text { público }\end{array}$ & Vehículos & $\begin{array}{c}\text { Regiones } \\
\text { metropolitanas }\end{array}$ & $\begin{array}{l}\text { Viviendas } \\
\text { habitadas }\end{array}$ & $\begin{array}{l}\text { \% Entregan } \\
\text { a servicio } \\
\text { público }\end{array}$ & Vehículos \\
\hline V. Ecatepec & 559,300 & 92.4 & 120 & XVII. Toluca & 262,733 & 84.2 & 149 \\
\hline III. Chimalhuacán & 424,428 & 97.9 & 94 & VIII. Metepec & 83,247 & 93.8 & 48 \\
\hline IV. Cuautitlán Izcalli & 398,506 & 94.0 & 185 & VII. Lerma & 85,045 & 93.5 & 68 \\
\hline IX. Naucalpan & 322,555 & 90.6 & 243 & & 431,025 & & 265 \\
\hline X. Nezahualcóyotl & 280,211 & 98.9 & 139 & & & & \\
\hline I. Amecameca & 251,907 & 90.0 & 88 & Regior & es rural-urb & & \\
\hline XVIII. Tultitlán & 301,469 & 96.4 & 79 & II. Atlacomulco & 172,616 & 67.9 & $82 *$ \\
\hline XVI. Tlalnepantla & 198,582 & 96.6 & 138 & VI. Ixtlahuaca & 162,862 & 60.7 & \\
\hline XV. Texcoco & 92,479 & 89.0 & 43 & & & & \\
\hline & $2,829,437$ & & 1,129 & & & & \\
\hline \multicolumn{3}{|l|}{ Regiones hinterland } & & \multicolumn{3}{|c|}{ Regiones rurales } & \\
\hline XI. Otumba & 105,460 & 88.7 & & XII. Tejupilco & 93,739 & 68.2 & \\
\hline XX. Zumpango & 111,127 & 87.9 & 83 & XIII. Tenancingo & 93,739 & 91.9 & \\
\hline XIV. Tepotzotlán & 83,250 & 93.6 & & $\begin{array}{l}\text { XIX. Valle de } \\
\text { Bravo }\end{array}$ & 85,302 & 60.3 & \\
\hline
\end{tabular}

Fuente: Elaboración propia datos INEGI, 2014, INEGI, 2015.

La Encuesta Nacional de Gobiernos Municipales (INEGI, 2017) registró 2,479 vehículos con antigüedad entre 1990 y 1999 (39\%), 2000 a 2016 (61\%), compactador (48\%); con caja abierta (46\%) y otro (7\%), 50\% y más de los vehículos utiliza diésel y 34\% gasolina.

La quema de basura, en proporción de viviendas $50 \%$ y $85 \%$ es representativa de San José del Rincón, Sultepec, San Felipe del Progreso, Ixtapan del Oro, Villa de Allende, Villa Victoria, 
Acambay de Ruíz Castañeda, Zacualpan. En el rango de 40\% a 49\%, Almoloya de Juárez, Amatepec, Texcaltitlán, Ixtlahuaca, Tlatlaya y Temascaltepec.

En sesenta y ocho municipios se distribuyen 71 sitio de disposición final, régimen de administración municipal (82\%); intermunicipal (1.4\%); concesión (14\%) y otro. Destacan los rellenos sanitarios de Tepotzotlán, Bordo Poniente y Puerto de Chivos, Tultepec, Juchitepec, Zinacantepec y el vertedero de Xonacatlán. En proceso proyectos que propone la clausura y saneamiento del tiradero a cielo abierto y construcción del relleno sanitario tipo $\mathrm{C}$ en el municipio de Apaxco, construcción de un biodigestor en el centro integral de manejo de residuos de Atlacomulco, para generación de energía eléctrica y gas combustible (SMA, 2018).

En la entidad el uso consuntivo de agua 2,762 (hm/año) se destina al abastecimiento público $49 \%$; agrícola $43 \%$, industria autoabastecida $7 \%$ y generación de energía eléctrica $1 \%$. Se cuenta con doce plantas potabilizadoras en operación, capacidad instalada 22.171 (m3/s) y caudal procesado $16.744(\mathrm{~m} 3 / \mathrm{s})$.

Los servicios de agua potable, drenaje, alcantarillado, tratamiento y disposición de aguas residuales están a cargo de organismos operadores descentralizados de los gobiernos locales. 124 municipios proveen servicio de agua potable, 123 drenaje y alcantarillado, 56 informan tratamiento de aguas residuales, ochenta facturan el servicio de cuota fija, muy pocos el servicio medido y 13 facturan servicio de agua en tomas industriales. Tomas de agua para abastecimiento 1,286, las fuentes principales son pozos $(79.5 \%)$ y manantiales (19\%). Treinta y dos municipios ejecutan programas para la gestión sustentable de los servicios de agua potable, doce en el ámbito municipal, cinco estatal y 31 federal, treinta y siete operan sistemas de información sobre la opinión de los usuarios (INEGI, 2017). En zonas urbanas el acceso, disponibilidad de agua potable dentro de la vivienda o predio y drenaje tiene cobertura superior a $96 \%$, en zonas rurales $87 \%$ y $89 \%$, drenaje $80 \%$ incluye fosa séptica. (CONAGUA, 2017: 88-197). La calidad de agua superficial muestra deficiencia de DBO5 y DQO (Cuadro 7).

Se dispone de plantas de tratamiento municipales: cuenca del río Pánuco, 114, cuenca del río Balsas, 45 y cuenca del río Lerma, 52. La entidad genera un volumen de aguas residuales de 1,586.94 hm3 /año, permisos de descargas otorgados a los municipios, 48.7 $\mathrm{hm} 3 / \mathrm{año}$ o $3 \%$ del volumen total, recibe tratamiento $18.9 \%$. Las aguas residuales se vierten en 632 puntos de descarga, corrientes de agua superficial 49\%; río o arroyo 495; canal o dren 19\%; suelo o barranca $10 \%$; gran colector 5.3\%; otro, lago o laguna y presa (INEGI, 2017). 
Cuadro 7

Número de sitios y parámetros de calidad de agua en el Estado de México

\begin{tabular}{|l|l|l|l|l|l|l|}
\hline & \multicolumn{1}{|c|}{$\begin{array}{c}\text { Sitios de } \\
\text { monitoreo }\end{array}$} & \multicolumn{1}{|c|}{ Excelente } & Buena calidad & Aceptable & Contaminada & $\begin{array}{l}\text { Fuertemente } \\
\text { contaminada }\end{array}$ \\
\hline DBO5 & 111 & 9.30 & 17.60 & 29.70 & 28.70 & 14.80 \\
\hline DQO & 112 & 3.70 & 17.40 & 7.30 & 44.0 & 27.60 \\
\hline SST & 112 & 27.50 & 36.70 & 22.0 & 13.80 & --------- \\
\hline
\end{tabular}

Fuente: Elaboración propia datos CONAGUA, 2017. hectómetro cúbico, $1 \mathrm{hm} 3=1000000 \mathrm{m3}$.

\section{$\rightarrow$ 3. Conclusiones.}

La flexibilidad con la que se adaptan a la coyuntura sociopolítica los instrumentos de planeación está condicionada por los cambios de administración, el tiempo que consume la conciliación y la aprobación. Gómez MacFarland (2017) analizó la calidad de la norma jurídica en la planificación para el desarrollo municipal. En el Estado de México existen disposiciones que determinan criterios de planeación, la presencia de un comité de planeación para el desarrollo estatal y homólogos municipales, la participación ciudadana en los procesos de planeación y la elaboración de diagnósticos municipales. Precisa que la libertad política y administrativa del municipio ofrece oportunidades para consolidar el federalismo democrático y la diversidad de carencias lleva a los gobiernos locales a mantenerse como gestores de programas públicos de órdenes superiores de gobierno, acota ausencia de lineamientos e indicadores de evaluación de resultados.

El modelo de planificación soporte de la gestión de las políticas públicas debe contener elementos nucleares de la directriz: los objetivos, las estrategias para lograrlos; los recursos humanos, técnicos y financieros necesarios; los criterios de seguimiento y evaluación. Gómez (2012) y García (2010) coinciden en que la planeación como praxis, conjuga voluntades, esfuerzos, talentos, recursos, compromisos y disciplina de tomadores de decisiones y grupos sociales en cumplimiento de responsabilidades. El ascenso de una nueva generación de políticas públicas en las que se pretende la participación del capital privado y de actores locales, organismos civiles, instancias de gobierno estatales y municipales, tiene el reto de impulsar las potencialidades productivas regionales, disminuir los contrastes sociales y asimetrías territoriales.

González y Gil-García (2008) consideran que el gobierno electrónico es un mecanismo democratizador y analizaron 32 portales. El Estado de México obtuvo la posición dos después de Nuevo León, los resultados de la evaluación expresan inclusión 14\%; deliberación 20\%; ciudadanía $13 \%$, legitimidad $12 \%$, total 59\%. La legitimidad expresa la importancia que tiene a nivel político la 
imagen del gobierno. La participación ciudadana debe cobrar mayor importancia en las estrategias de gobierno digital, no es deseable y suficiente que las decisiones estén en poder de pocas manos. Los ciudadanos informados, en uso de sus derechos, deben participar en la dirección que lleva el gobierno y las tecnologías son muy importantes en el proceso de cambio. Es indispensable que la ciudadanía exija las oportunidades de participación en las decisiones en medios electrónicos y presenciales.

El Plan Estatal de Desarrollo 2017-2023 conto con opiniones y propuestas obtenidas de cinco foros de consulta ciudadana y medios electrónicos sobre líneas de atención de los objetivos de desarrollo sostenible. Dimensión social: fin de la pobreza, hambre cero, Salud y bienestar. Económica: educación de calidad, trabajo y crecimiento económico, industria, innovación e infraestructura, producción y consumo responsable. Territorial: energía asequible y no contaminante, ciudades y comunidades sostenibles, acción por el clima, vida y ecosistemas terrestres. Seguridad: igualdad de género, paz, justicia e instituciones sólidas. Transversal: reducción de las desigualdades, alianza para lograr los objetivos y sinergia institucional. La participación social se legitimó con 5,100 asistentes a los foros y 1,021 opiniones en la plataforma digital (GEM, 2018:30).

Gasca (2009) señala que la regionalización persigue objetivos para la gestión pública, la programación, el financiamiento, la instrumentación de proyectos, la orientación de patrones y estrategias de desarrollo económico, social y territorial, la planeación y el ordenamiento territorial. Apunta debilidades en el diseño de las regiones plan o programa, identifica un ejercicio intelectual, según diversos criterios y fines utilitarios, de tal forma que se vuelven regiones relativas, es decir lo que para un propósito es una región, para otro no lo es. Ello se debe a que responden a objetivos disímbolos y coyunturales, inscritos en las políticas gubernamentales durante determinados períodos.

La prioridad de la materia urbana se sustenta en el Plan Estatal de Desarrollo Urbano, representa un avance en la incorporación de las premisas de la Nueva Ley General de Asentamientos Humanos, Ordenamiento Territorial y Desarrollo Urbano y la visión de la nueva agenda urbana. Sin embargo, la regionalización del sistema urbano y las regiones programa responden a objetivos de gestión distintos. En lo general la primera se afianza en el pilar territorial: ciudades y comunidades sostenibles, la segunda en el pilar económico que plantea impulso a las vocaciones regionales para crear empleos.

Las políticas urbanas dependen de los criterios de la administración y control de los usos de suelo, establecidos en el libro Quinto del Ordenamiento Territorial de los Asentamientos Humanos y del Desarrollo Urbano de los Centros de Población del Código Administrativo del Estado de México. La OCDE (2007) propone formular políticas públicas que aborden no solo lo económico, también lo social y ecológico y superar el modelo de gestión centrada en la administración de los usos de suelo. Pone en tela de juicio la eficacia de las tradicionales estructuras y prácticas de planificación de los 
gobiernos locales, advierte la necesidad de diseñar nuevos estilos de operación en concordancia con la gobernanza. Lo cual exige cambios en las prácticas jerárquicas y decididas burocráticamente, regidas por normas y reglamentos.

El índice de prosperidad ofrece un diagnóstico descriptivo de menos de la mitad de los municipios. El índice débil, moderadamente débil, moderadamente sólido prescribe priorizar y fortalecer la política urbana. Vásquez (2013:220) distingue la política urbana como aquella que se refiere al poder urbano, las políticas públicas urbanas se ocupan de aspectos institucionales y materiales, es decir, quiénes y cómo se producen políticas públicas sobre las ciudades y las áreas o sectores de políticas públicas significativas en el tratamiento de los problemas urbanos. Coincide en que la gobernanza aporta elementos para fortalecer los procesos de coordinación entre los agentes responsables y participantes en la formulación de políticas públicas urbanas.

No solo se trata del problema socio organizativo, la debilidad de la legislación urbana advierte inconsistencias en el sistema procesual que debiese impulsar o fortalecer las políticas públicas urbanas. El asunto no es menor ante la debilidad del marco jurídico la anarquía urbana se hace patente en los espacial, lo económico, social y ambiental.

Los nodos de actividad económica con índices de productividad sólidos se corresponden con índices de sostenibilidad ambiental débil o muy débil, la relación inversa adelanta que la productividad económica, no es convergente con el desarrollo urbano sostenible. El perfil de las administraciones locales ratifica la heterogeneidad de capacidades para el ejercicio de la planeación, la gestión y operación del ordenamiento territorial y desarrollo urbano sostenible. La implementación de acciones de sostenibilidad urbana acota las estrategias de ciudad compacta, aprovechamiento de predios baldíos, incipiente ampliación de ciclo vías, impulso de transporte masivo y pocos municipios que declaran vinculación con el gobierno estatal para impulsar el desarrollo urbano. Es sintomática la limitada concepción que se tiene sobre la sostenibilidad urbana y el bajo nivel de interlocución intergubernamental para impulsarla.

El aumento de la población y la aglomeración urbana fungen como factores de presión medioambiental. La movilidad de la población a través de los vehículos en circulación y las fuentes fijas incentivan la emisión de gases criterio que alteran la calidad del aire y la salud de las personas.

Los municipios se ocupan de la recolección y la disposición final de grandes volúmenes de residuos sólidos. Rodríguez $(2008: 57,148)$ afirma las administraciones locales han visto el manejo de los residuos sólidos como prestación del servicio de recolección y limpia, pocos en la perspectiva de gestión integral (tasa de generación, métodos de recolección, diseño de rutas, unidades de recolección, transporte, estaciones de transferencia, reciclaje, aprovechamiento y método de disposición). El sustento legal del Estado de México permite a los municipios cobrar por limpiar los 
predios baldíos, transporte de los residuos resultantes y la recolección en comercios e industrias. La evaluación de rutas, elaboración de reglamentos y la coordinación entre áreas y sectores de gobierno pueden mejorar el desempeño municipal en el manejo integral de los residuos sólidos urbanos.

La tendencia para el período 2016-2030 indica que más de la mitad del crecimiento poblacional ocurrirá en regiones hidrológicas que albergan municipios del Estado de México: IV Balsas, VIII Lerma-Santiago-Pacífico y XIII Aguas del Valle de México, en las que existe un grado de presión hídrica mayor al nacional (CONAGUA, 2017). Las áreas de atención identifican la contaminación del agua superficial y la sobreexplotación de aguas subterráneas, fuente principal de los servicios de agua pública.

El Programa Sectorial de Desarrollo Agrario, Territorial y Urbano 2020-2024 establece el ordenamiento territorial como política de Estado en las escalas locales, metropolitanas, regionales y nacional en sus dimensiones ambientales, sociales, culturales y económicas de desarrollo. Plantea objetivos y líneas de acción abundantes y metas de alcance conservador. Las isotopías identifican la regulación de usos de suelo y la propiedad urbana, rural y agraria, la concertación y el involucramiento de los agentes públicos, privados, sociales y la población, la equidad y la igualdad de acceso al desarrollo, son enunciativas las cuestiones ecológicas y la armonización de los instrumentos de gestión urbana (Gobierno de México, 2020).

Si la política es el arte de hacer el bien a todos, la política de ordenamiento territorial no solo involucra el uso y aprovechamiento del suelo, sino el conjunto de normas jurídicas que legislen la armonización de los instrumentos de gestión urbana (CONAPO, 2018) y las crecientes necesidades insatisfechas, suministro de agua, tratamiento de aguas servidas y manejo de residuos sólidos.

La gobernabilidad democrática es una estrategia de construcción de capacidades que depende de la relación entre el sistema institucional, las capacidades de los actores políticos y sociales y la calidad del liderazgo transformacional (Rivas, 2012:328). El objeto final de la praxis será efectivo mediante la incorporación causal del territorio, donde se comprenden las prioridades, es decir, qué requiere la población y cómo el Estado o su entidad de administración territorial puede convergir en relación con políticas públicas pertinentes, cumpliendo sus compromisos sociales y de gestión de recursos (Gutiérrez et al, 2017).

La visión de los gobernantes, las políticas y las decisiones públicas tejen oportunidades o amenazas para avanzar o no en las expectativas de desarrollo sostenible. Se identifican fisuras de operación: debilidad o ausencia de un marco jurídico vinculante, coordinación vertical y horizontal de los agentes públicos y heterogeneidad en las aptitudes para el ejercicio de la planeación, ordenamiento territorial y desarrollo urbano sostenible. 
Toda vez que se incorporan los principios de desarrollo sostenible se legitima el discurso, el diagnóstico y los instrumentos de gestión e intervención. En términos generales prevalece el enfoque técnico de la planeación y ordenamiento territorial, que pretende resolver los conflictos de equidad asociados a la administración de los usos de suelo, los alcances ecológico y social quedan como externalidades positivas que se lograrán a través del impulso económico de la industria, comercio y los servicios y sin el sostén de un marco jurídico y territorial vinculante.

El crecimiento de la población, la aglomeración urbana, la actividad económica y social y sistemas sanitarios deficientes difunden la insostenibilidad ambiental en las distintas escalas territoriales, la problemática conjuga el deterioro de la calidad del aire, el déficit de suministro de agua, contaminación por vertido de aguas residuales y desechos sólidos, la situación es inherente no solo al incumplimiento de los compromisos y las atribuciones de los gobiernos en turno, también es resultado de las conductas de la población.

El desarrollo regional y urbano plantea desafíos inherentes a la gestión pública, no solo entendida como un ejercicio técnico y gerencial para la consecución de resultados de corto plazo, más como un proceso social coadyuvante en la creación de oportunidades y capacidades desarrollo.

Las administraciones municipales 2018-2021 por concluir aproximan la nueva generación con visiones y proyectos particulares que configuran curvas de aprendizaje amplias que requieren guías consistentes para fortalecer capacidades de interlocución e innovación. Los gobiernos estatales y municipales deberán esforzarse para cohesionar y coordinar el trabajo no solo en la regulación de usos de suelo, más en la formulación de políticas públicas y acciones incluyentes de las necesidades sociales, control de las emisiones de gases contaminantes de fuentes fijas y móviles, suministro de agua, tratamiento de aguas servidas y manejo integral de residuos sólidos en los ámbitos urbano y rural.

La demarcación de veinte regiones validadas técnica y políticamente representa una oportunidad de base territorial para formular programas de desarrollo regional y políticas públicas que direccionen los objetivos sociales, económicos y medioambientales. Un marco jurídico vinculante constituye un componente transversal de desarrollo sostenible en la medida que establezca mecanismos para potencializar y fortalecer las aptitudes de negociación y toma de decisiones de los gobiernos municipales, garantice la inclusión de los avances y retrocesos que retroalimenten instrumentos de planeación, políticas públicas y procesos de gestión de largo plazo.

Las amenazas identifican la carencia de institucionalización de la política de desarrollo regional que debiera sostener el sistema de decisión que articule los procedimientos para potencializar las capacidades organizativas municipales para diseñar los programas regionales que contengan los objetivos, las políticas públicas, las estrategias de intervención, la evaluación de los resultados como 
insumos de ajuste y mejora. La instrumentalización de las regiones programa representa una carga administrativa adicional sujeta a las prioridades determinadas por la visión, el proyecto y las acciones del gobierno en funciones. 


\section{Bibliografía y referencias documentales}

Arellano, David, y Cabrero, Enrique (2005). La Nueva Gestión Pública y su teoría de la organización: ¿son argumentos antiliberales? Justicia y equidad en el debate organizacional público. Gestión y Política Pública, XIV (3),599-618. Disponible en: https://www.redalyc.org/articulo.oa?id=133/13314307

Barreto-Villanueva, Adán. (2012). El progreso de la Estadística y su utilidad en la evaluación del desarrollo. Papeles de población, 18(73), 241-271. Recuperado de http://www.scielo.org.mx/scielo.php?script=sci arttextypid=S1405$\underline{74252012000300010 y \operatorname{lng}=\text { esytlng=es. }}$.

Barros Valero, Javier. (2009). América Latina. Administración Pública y Gobernanza, Revista de Administración Pública 120, volumen XLIV, No. 3, p. 143 -154, disponible en: https://inap.mx/wpcontent/uploads/2020/09/INAP-RAP 120-2009.pdf

Cabrero-Mendoza, E. (Coord.) (2009), Competitividad de las ciudades en México. La nueva agenda urbana, México, CIDE: secretaria de Economía

Cárdenas, Viviana (2006). Reseña de "Semántica interpretativa" de François Rastier. Tópicos del Seminario, (16),172-177. Disponible en: https://www.redalyc.org/articulo.oa?id=594/59401608

Cardozo Brum, Myriam. (2013). Políticas públicas: los debates de su análisis y evaluación. Andamios, 10(21), 39-59. Recuperado de http://www.scielo.org. $\mathrm{mx} / \mathrm{scielo}$.php?script=sci arttextypid=S187000632013000100003ylng=esytlng=es.

Centro de Estudios Sociales y de Opinión Pública (2018). Las ciudades mexicanas. El perfil de la población y las escalas de prosperidad. Documento de trabajo 294. Cámara de Diputados LXIV Legislatura, México, México.

Comisión Nacional del Agua (2017). Estadísticas del Agua en México. Secretaría de Medio Ambiente y Recursos Naturales, México, México. http://sina.conagua.gob.mx/publicaciones/EAM 2017.pdf

Comisión Nacional del Agua (2012-2018). Base de datos por Estados. Calidad del agua en México. Secretaría, recuperado de: https://www.gob.mx/conagua/articulos/calidad-del-agua

Consejo Nacional de Población (2016). Proyección de la población de los municipios a mitad de año por sexo y grupos de edad, 2010-2030, https://datos.gob.mx/busca/dataset/proyecciones-de-la-poblacion-demexico-y-de-las-entidades-federativas-2016-2050

Delgado Fernández, Santiago. (2004). Sobre el concepto y el estudio del liderazgo político. Una propuesta de síntesis. Psicología Política, no. 29, p. 7-24, disponible en: http://panel.inkuba.com/sites/2/archivos/Universidad\%20de\%20Granada\%20Delgado.pdf

Estados Unidos Mexicanos (2016). Ley General de Asentamientos Humanos, Ordenamiento Territorial y Desarrollo Urbano. Diario Oficial de la Federación 28 de noviembre de 2016, Cámara de Diputados del H. Congreso de la Unión, Secretaría General, Secretaría de Servicios Parlamentarios. México, México.

García Moctezuma, Francisco. (2010). La planeación del desarrollo regional en México (19002006). Investigaciones geográficas, (71), 102-121. Recuperado en 10 de agosto de 2020, de http://www.scielo.org.mx/scielo.php?script=sci arttextypid=S0188$46112010000100009 \mathrm{ylng}=\mathrm{esy}$ tlng=es.

Garza, Gustavo. Cabrero Mendoza, Enrique (coord.), Competitividad de las ciudades en México. La nueva agenda urbana. Estud. demogr. urbanos [online]. 2010, vol.25, n.2, pp.491-499. https://doi.org/10.24201/edu.v25i2.1359.

Gasca Zamora, José (2009). Geografía Regional. La región, la regionalización y el desarrollo regional en México. Temas selectos de geografía. IG. Universidad Nacional Autónoma de México.

Gobierno de la ciudad de México. (2020). Base de datos Red Automática de Monitoreo Atmosférico (RAMA). http://www.aire.cdmx.gob.mx/default.php?opc $=\% 27 \mathrm{aKBh} \% 27$ 
Gobierno de México (2020). Programa Sectorial de Desarrollo Agrario, Territorial y Urbano 2020-2024. Secretaria de Desarrollo Territorial y Urbano, México, México, recuperado de: https://www.gob.mx/sedatu/acciones-y-programas/programa-sectorial-de-desarrollo-agrarioterritorial-y-urbano-2020-2024

Gobierno del Estado de México (2001). Ley de Planeación del Estado de México y Municipios, decreto número 44. H. LIV Legislatura del Estado de México. Toluca de Lerdo, México; 11 de septiembre de 200. Publicación: 21 de diciembre del 2001, Vigencia: 01 de enero del 2002.

Gobierno del Estado de México. (2018). Dictamen de la División Regional, Periódico oficial. Gaceta de Gobierno, DGC número 0011021, 07 de septiembre, p.4-5.

Gobierno del Estado de México. (2018). Plan Estatal de Desarrollo 2017-2023. Comité de planeación de la administración pública, Consejo editorial de la administración pública, Toluca de Lerdo, México.

Gobierno del Estado de México. (2019). Acuerdo del Ejecutivo del Estado de México por el que se modifica el Plan Estatal de Desarrollo Urbano. Gaceta de Gobierno, DGC 001-1021, Tomo CCVIII, número 120, 23 de diciembre, Toluca, México.

Gobierno del Estado de México. (2020). Red de Monitoreo Atmosférico de la ZMVT. Reporte mensual junio 2020. https://rama.edomex.gob.mx/2020

Gómez MacFarland, Carla Angélica. (2017). Los planes de desarrollo municipal en México y la participación ciudadana. Un análisis del marco jurídico. Boletín mexicano de derecho comparado, 50(150), 11491177. https://doi.org/10.22201/iij.24484873e.2017.150.11836

González Díaz, J. G., García-Velasco, R., Ramírez-Hernández, J.-J., y Castañeda Martínez, T. (2013). La territorialización de la política pública en el proceso de gestión territorial como praxis para el desarrollo. Cuadernos De Desarrollo Rural, 10(72). https://doi.org/10.11144/Javeriana.cdr10-72.tppp

González Gómez, Javier. (2008). La mejora de la gestión y el enfoque hacia resultados en el ámbito internacional: ¿Qué hacer? ¿Hacia dónde ir? ¿Cómo actuar? Revista de Administración Pública 117, volumen XLIII, No. 3, p. 31-48, recuperado de: https://inap.mx/wp-content/uploads/2020/09/INAPRAP 117-2008.pdf

González, Fernando; Gil-García, Ramón J. (2008). e-Democracia y oportunidades de participación en los portales estatales mexicanos, pagina 107-116. Revista de Administración Pública. Nueva Época 117, Volumen XLIII, $\mathrm{N}^{\mathrm{o}} 3$, p. 31-48, https://inap.mx/wp-content/uploads/2020/09/INAP-RAP 1172008.pdf

Gutiérrez, JA., Restrepo, RD., Zapata, JS, Stivens, J. (2017). Formulación, implementación y evaluación de políticas públicas desde los enfoques, fines y funciones del Estado, Revista CES Derecho, (8), 2, pp. 333-351, recuperado de: http://www.scielo.org.co/pdf/cesd/v8n2/v8n2a08.pdf

https://www.inegi.org.mx/app/indicadores/?t=274yag=15

Instituto Nacional de Estadística Geografía e Informática. INEGI. (2015). Encuesta intercensal, recuperado de: https://www.inegi.org.mx/programas/intercensal/2015/\#Tabulados

Instituto Nacional de Estadística, Geografía e Informática. (2017). Censo Nacional de Gobiernos Municipales y Delegacionales. Aguascalientes, México. https://www.inegi.org.mx/programas/cngmd/2017/

Instituto Nacional de Estadística, Geografía e Informática. (2018). México en cifras. Banco de indicadores, https://www.inegi.org.mx/app/indicadores/?t=274yag=15\#tabMCcollapse-Indicadores

Lahera, Eugenio. (2004). Política y Políticas Públicas. Serie Políticas Sociales, número 95, Cepal. División de Desarrollo Social, Santiago de Chile.

Lezama, José Luis, y Domínguez, Judith. (2006). Medio ambiente y sustentabilidad urbana. Papeles de población, 12(49),

153-176.

Recuperado

de http://www.scielo.org.mx/scielo.php?script=sci arttextypid=S140574252006000300007ylng=esytlng=es.

Lopera Medina, Mónica María. (2014). Aspectos históricos y epistemológicos de la planificación para el desarrollo. Revista Gerencia y Políticas de Salud,13(26), 28-43. Recuperado de http://www.scielo.org.co/scielo.php?script=sci arttextypid=S1657$\underline{70272014000100003 y \operatorname{lng}=\text { enytlng=es. }}$ 
Matus Lobos, Pablo. (2015). Isotopías del discurso político chileno: El caso de la Franja Presidencial 2013. Cuadernos.info, (37), 187-199. https://dx.doi.org/10.7764/cdi.37.739

Montero Bagatella, Juan Carlos. (2012). Gobernabilidad: Validez/Invalidez o moda del concepto. Revista mexicana de ciencias políticas y sociales,57(216), 09-23. Recuperado de http://www.scielo.org.mx/scielo.php?script=sci arttextypid=S018519182012000300001 ylng=esytlng=es.

ONU-HABITAT. (2016). Índice de las ciudades prosperas en la República Mexicana. Reporte nacional de tendencias de la prosperidad urbana en México. México.

ONU-HABITAT. (2019). Reporte nacional de prosperidad urbana. Índice de las ciudades prosperas, OnuHábitat, Infonavit, Gobierno de México, Desarrollo Territorial, México, http://70.35.196.242/onuhabitatmexico/cpi/Reporte-CPI-2019.pdf

Organización de las Naciones Unidas. (2017). La Nueva Agenda Urbana en español. Secretariado de Hábitat III, http://onuhabitat.org.mx/index.php/la-nueva-agenda-urbana-en-espanol

Organization for Economic Co-operation and Development. (2007). Competitive cities: a new entrepreneurial paradigm in spatial development. Territorial Reviews, recuperado de http://www.oecd.org/cfe/regional-policy/38747575.pdf

Parales-Quenza, Carlos José, y Vizcaíno-Gutiérrez, Milcíades. (2007). Las relaciones entre actitudes y representaciones sociales: elementos para una integración conceptual. Revista Latinoamericana de Psicología, 39(2), 351-361. Disponible en: http://www.scielo.org.co/scielo.php?script=sci arttextypid=S0120$05342007000200010 y \operatorname{lng}=$ enytlng=es.

Penagos García, Sergio. (2008). La reconversión de los procesos gubernamentales en México con un enfoque hacia la mejora, el desempeño y los resultados. Revista de Administración Pública 117, volumen XLIII, No. 3, p. 13-30, recuperado de: https://inap.mx/wp-content/uploads/2020/09/INAP-RAP 1172008.pdf

Rathe, L. (2017). La sustentabilidad en los sistemas socioe-cológicos. Utopía y Praxis Latinoamericana, 22 (78), p. 65-78.

Rivas Otero, José Manuel. Liderazgo político y gobernabilidad en América Latina: una aproximación teórica y metodológica (2012). XV Encuentro de Latinoamericanistas Españoles, noviembre, Madrid, España. pp. 312-334, disponible en: https://halshs .archives-ouvertes.fr/halshs-00874102/document

Rodríguez Lepure, Ana Lucía (2008) “Gestión local e intergubernamental de los residuos sólidos urbanos. Una evaluación de las “buenas prácticas” en los municipios mexicanos”, tesis maestría, México, El Colegio de la Frontera Norte, A.C., https://www.colef.mx/posgrado/wp-content/uploads/2009/06/TESISRodr\%C3\%ADguez-Lepure-Ana-Luc\%C3\%ADa-MAIA.pdf

Secretaría del Medio Ambiente (2018. Proyectos. Gobierno del Estado de México, https://sma.edomex.gob.mx/proyectos

Vásquez Cárdenas, Ana Victoria. (2013). Las políticas públicas urbanas como proceso plural. Enfoques de política y gobernanza urbanas. Estudios Políticos, 42, Instituto de Estudios Políticos, Universidad de Antioquia, pp. 218-241. http://www.scielo.org.co/pdf/espo/n42/n42a11.pdf 


\section{Números anteriores}

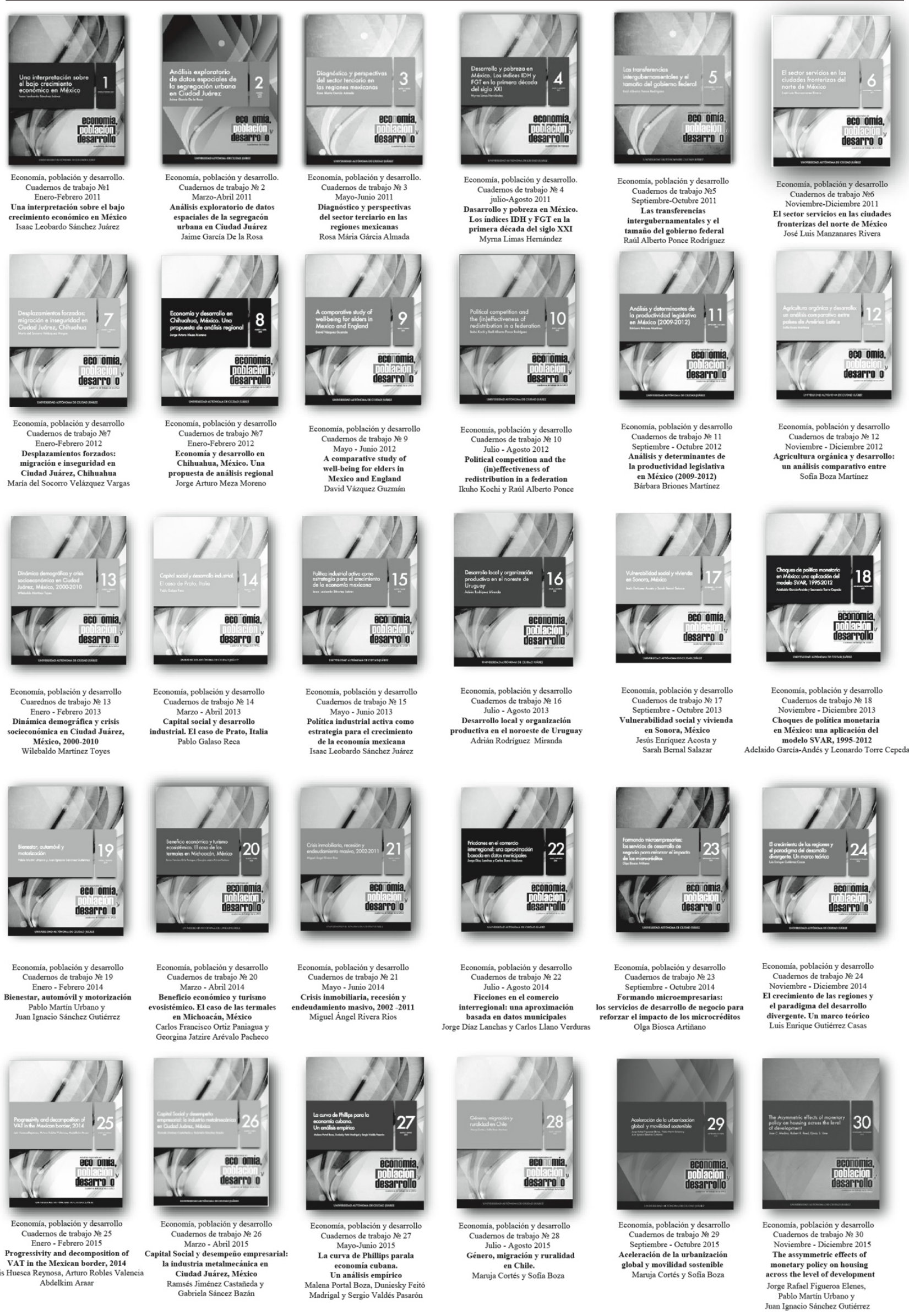



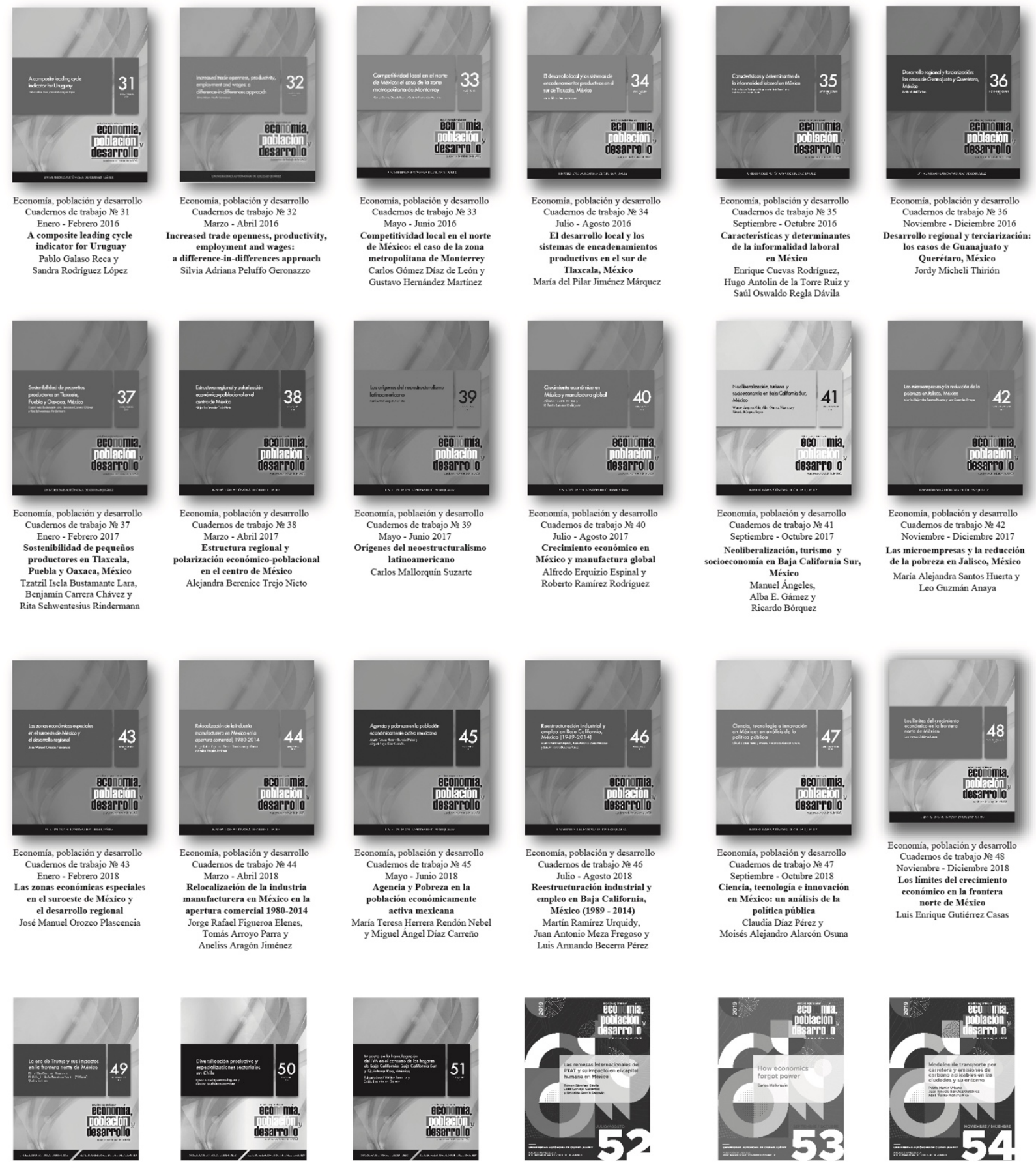

Economia, población y desararollo
Cuadernos de trabajo No 49
Enero - Febrero 2019

La era de Trump y sus impactos
en la frontera norte de Mérico

Dirección General doroeste

Varios autores

Economia, población y desarrollo
Cuadernos de trabajo № 50 Marzo - Abril 2019

Diversificación productiva y
especializaciones sectoriales en Chile

Economia, población y desarrollo
Cuadernos de trabajo № 51 Mayo - Junio 2019
Impacto de la homologación del IVA
en el consumo de los hogares de en el consumo de los hogares de
Baja Califoria, Baja Califoria Sur Ignacio Rodriguez Rodriguez
Paulina Sanhueza Martinez
Economiá, población y desarrollo
Cuadernos de trabajo № 52 gosto 2019 Las remesas internacionales
del PTAT y su impacto en el capital humano
ent Romin Sánchez Dávila Lidia Carvajal Gutiérrezy
Oswaldo Garcia Salgado Rolando Israel Valdez Ramirez y
Emilio Hermaindez Gómez
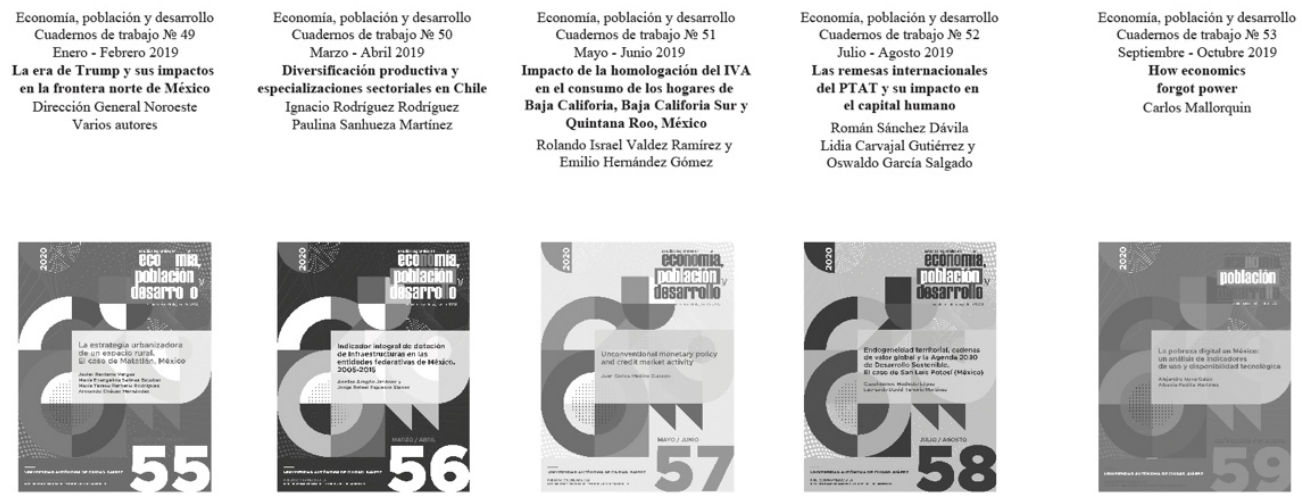

Economia, población y desarrollo
Cuadernos de trabajo № 54 Noviembre - Diciembre 2019
Modelos de transporte por carretera y Modelos de transporte por carretera y
emisiones de carbono aplicables en las ciudades y su entorno Pablo Martin Urbano,
Juan Ignacio Sánchez Gutierrez
y Abril Yuriko Herrera Rios

Economia, población y desarrollo Enero - Febrero 2020 La estrategia urbanizadora
de un espacio rural. de un espacio rural.
El caso de Matatlán, México Javier Renteria Vargas, Maria Evangelina Salinas Escobar,
Maria Teresa Renteria Rodriguez Armando Chávez Hernánde

Economia, población y desarrollo
Cuadermos de trabajo No 56 Cuademos de trabajo o
Marzo-Abril 2020 Indicador integral de dotación de
infraestructuras en las entidades Tederativas a 2015 Aneliss Aragón Jiménez y
Jorge Rafael Figueroa Elenes
Economia, población y desarrollo
Cuadernos de trabaje No 57 Mayo - Junio 2020

Unconventional monetary policy
and creditmarket activity Juan Carlos Medina Guirado
Economia, población y desarrollo Cuadernos de trabajo.
Julio - Agosto 2020 Endogeneidad territorial, cadenas de valor global y la
Agenda 2030 de Desarrollo Sostenible. Agenda 2030 de Desarrollo Sostenible Cuauhtémoc Modesto López y
Leonardo David Tenorio Martinez
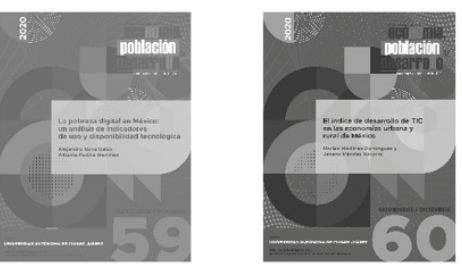

Economia, población y desarrollo Septiembre - Octubre 2020 La pobreza digital en México: disponibilidad tecnológica Alejandro Nava Galán y
Economia, población y desarrollo de trabajo № El indice de desarrollo de TIC en las economias
urbana y rural de México Marlen Martinez Domingue zy 
Números anteriores
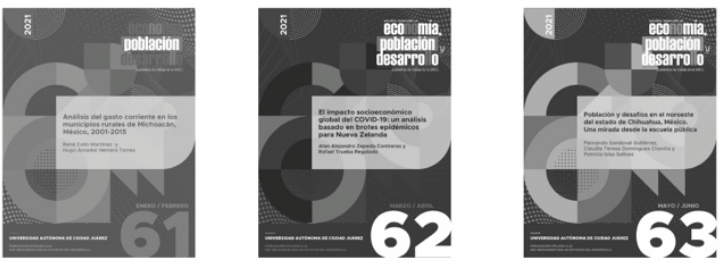

Economía, población y desarrollo
Cuadernos de trabajo No 61 Enero - Febrero 2021

municipios rurales de Michoacín.

México, 2001-2015

Economia, población y desarrollo

Cuadernos de trabajo Né 62

Economia, población y desarrollo
Cuadernos de trabajo Né 63 Mayo - Junio 2021

El impacto socioeconómico
global del COVID-19:

un anailisis basado en
brotes epidemicos para

René Colin Martinez y
Hugo Amador Herrera Torre

Alan Alejandro Zepeda Contreras

Jado de Chihuahua, Meresice

escuela pública

Fermando Sandoval Gutiérrez,
Claudia Teresa Dominguez Chavir

y Patricia Islas Salinas 


\section{Para el documento general:}

Tipo de letra: Times New Roman.

Tamaño: 11 puntos.

Interlineado: 1.5 espacios.

Títulos y subtítulos:

El texto principal en 11 puntos. Títulos 12 puntos (en resaltado). Subtítulos 11 puntos. Cada título y subtítulo deberá numerarse bajo el siguiente orden: 1, 1.1, 2, 2.1, 2.2...

La extensión máxima de los cuadernos de trabajo será de 40 cuartillas.

La primera vez que se emplee una sigla en el texto se especificará primero su equivalencia completa y después la sigla.

\section{Hoja de presentación:}

Título:

14 puntos, centrado, resaltado.

Nombre de autor(es):

12 puntos

Resumen y abstract:

Debe incluir resumen en español y abstract (diez puntos), no mayor a 250 palabras

Palabras clave:

Incluir entre tres y cinco palabras clave, en español e inglés

Referencia del autor o autores:

Institución de adscripción, grado académico y líneas-grupos de investigación que desarrolla y a los que pertenece.

\section{Sistema de referencia de citas:}

Harvard-APA

Las citas bibliográficas en el texto deberán incluir entre paréntesis sólo el apellido del autor, la fecha de publicación y el número de página; por ejemplo: (Quilodrán, 2001: 33).

\section{Notación en sección de bibliografía y fuentes de información:}

Se deberá incluir al final del texto. Toda referencia deberá estar mencionada en el texto o notas de pie de página.

Cada referencia iniciará con el primer apellido o los apellidos, luego el nombre del autor, y después, entre paréntesis, el año de publicación seguido de un punto. Ejemplos:

Se deberá incluir al final del texto. Toda referencia deberá estar mencionada en el texto o notas de pie de página.

Cada referencia iniciará con el primer apellido o los apellidos, luego el nombre del autor, y después, entre paréntesis, el año de publicación seguido de un punto. Ejemplos: 
Artículo:

Ros, Jaime (2008). "La desaceleración del crecimiento económico en México desde 1982", en Trimestre Económico, vol. 75, núm. 299, pp. 537-560.

Libro:

Villarreal, René (2005). Industrialización, competitividad y desequilibrio externo en México.

Un enfoque macroindustrial y financiero (1929-2010), México, Fondo de Cultura Económica.

Capítulo de libro:

Castillo, Manuel Ángel (2003). "La política de inmigración en México: un breve recuento", en Manuel Ángel Castillo, Alfredo Lattes y Jorge Santibáñez (coords.), Migración y fronteras, Tijuana,

El Colegio de la Frontera Norte / Asociación Latinoamericana de Sociología / El Colegio de México, pp. 425-451.

\section{Notas de pie de página:}

Se utilizarán para hacer indicaciones complementarias, aclaraciones o ampliación de una explicación. La nota de pie de página en Times New Roman, 10 puntos.

\section{Tipología de imágenes dentro del texto:}

Cuadro

Gráfica

Diagrama

Mapa

Figura

Todas las imágenes deben ser numeradas y mencionadas dentro del texto. A toda imagen debe incluirse la fuente.

Las indicaciones de la imagen: tipo y número de imagen, título de imagen y fuente se escriben en 10 puntos. En el texto poner como imagen los mapas, figuras, gráficas y diagramas -con el ánimo de no perder el formato realizado por el autor.

\section{Ecuaciones y fórmulas:}

Si se utilizan ecuaciones o fórmulas deberá utilizarse el editor de ecuaciones de Word y numerarse.

\section{Envío de trabajos}

Los trabajos deben ser enviados a la dirección de correo: lgtz@uacj.mx. Con el Dr. Luis Enrique Gutiérrez Casas, editor de esta publicación.

La aceptación de cada colaboración dependerá de la evaluación de dos dictaminadores especialistas en la materia que se conservarán en el anonimato, al igual que el autor (autores) para efectos de la misma. 


\section{For General Document:}

Font type: Times New Roman.

Size: font size 11.

Paragraph: 1.5 line spacing.

Titles and subtitles: Main text font size 11. Titles font size 12 (Bold). Subtitles font size 11.

Each title and subtitle should be numbered in the following order: 1, 1.1, 2, 2.1, 2.2...

The maximum length of the workbooks will be 40 pages.

The first time an abbreviation is used in the text will be specified first complete equivalence and then stands.

\section{Front cover:}

Title:

Font size 14, centered, Bold.

Author name(s):

Font size 12.

Abstract:

It should include abstract in Spanish and abstract (font size 10), no more than 250 words.

Keywords:

Include three to five keywords, in Spanish and English.

Reference of author:

Institution of affiliation, academic degree and line-developed by research groups and belonging.

\section{Bibliographical appointment system:}

Harvard-APA

Citations in the text should include between parentheses only the author's name, publication date and page number, for example:

(Quilodrán, 2001: 33).

\section{Notation about Bibliography section and Information fonts:}

Should be included at the end of the text. All references must be mentioned in the text or footnotes page.

Each reference starts with the first name or last name, then the name of the author, and then, in parentheses, the year of publication followed by a period. Examples:

Article:

Ros, Jaime (2008). "La desaceleración del crecimiento económico en México desde 1982", en Trimestre Económico, vol. 75, núm. 299, pp. 537-560. 


\section{Editorial Guidelines}

Book:

Villarreal, René (2005). Industrialización, competitividad y desequilibrio externo en México. Un enfoque macroindustrial y financiero (1929-2010), México, Fondo de Cultura Económica.

Book chapter:

Castillo, Manuel Ángel (2003). "La política de inmigración en México: un breve recuento", en Manuel Ángel Castillo, Alfredo Lattes y Jorge Santibáñez (coords.), Migración y fronteras, Tijuana, El Colegio de la Frontera Norte / Asociación Latinoamericana de Sociología / El Colegio de México, pp. 425-451.

\section{Footnotes:}

Must be used to make additional indications, clarification or expansion of an explanation. The footnotes must be in Times New Roman, font size 10 .

\section{Image typology inside text:}

Picture

Graph

Diagram

Map

Figure

All images must be numbered and mentioned in the text, should include the source image. The indications of the image: type and number of image, image title and source are written in 10 font size. In the text set as image maps, figures, graphs and charts-with the intention of not losing the formatting by the author.

\section{Equations and Formulae:}

When using equations or formulas should be used in Microsoft Word equation editor and numbered.

\section{Paper sending}

Entries must be sent to the email address: lgtz@uacj.mx. With Dr. Luis Enrique Gutiérrez Casas, editor of this publication.

Acceptance of each collaboration will depend on the evaluation of two examiners skilled in the art to be kept anonymous, like the author(s) for the same purposes. 
Publicación afiliada a la

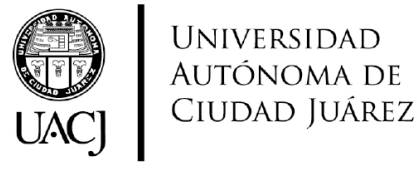

Red
RIED

Esta obra se editó y terminó de imprimir en Ciudad Juárez, Chihuahua, México 
